\title{
Multiple Utility Analyses for Sustainable Public Transport Planning and Management: Evidence from GPS-Equipped Taxi Data in Haikou
}

\author{
Jiawei Gui ${ }^{1,2,3, *(1)}$ and Qunqi $\mathrm{Wu}^{2,3}$ \\ College of Transportation Engineering, Chang'an University, Xi'an 710064, China \\ School of Economics and Management, Chang'an University, Xi'an 710064, China; wqq@chd.edu.cn \\ 3 Center of Comprehensive Transportation Economic Management, Chang'an University, Xi'an 710064, China \\ * Correspondence: gjw@chd.edu.cn
}

Received: 22 August 2020; Accepted: 28 September 2020; Published: 30 September 2020

check for updates

\begin{abstract}
The transportation utility values calculated by traditional utility methods are not comprehensive. Some objects and factors are ignored in traditional utility methods, and this narrow perspective is their primary drawback. In intelligent transportation systems, it is necessary to calculate transportation utility for promoting public traffic planning and management. To build a sustainable intelligent transportation system, modified utility methods are essential to analyze transportation utility in a comprehensive way with innovative technologies and efficient communication systems. To solve the disadvantages of traditional utility methods, it is necessary to establish a new method to build sustainable public transport in the future. In this study, the Multiple Utility Method and Transportation Utility Method are proposed for public transport planning and management from multiple perspectives. A sample is presented to provide a better description, and 69,174 GPS-equipped taxi data in Haikou are adopted for the application of the Transportation Utility Method. The results show that the transportation utility values calculated by the Transportation Utility Method are more comprehensive than the transportation utility calculated by traditional utility methods. This indicates that it is necessary to calculate transportation utility from multiple perspectives based on the Transportation Utility Method. Future directions could include improving the methods, considering more factors, expanding the data used, and extrapolating this research to other cities around the world with similar urban metrics and urban form.
\end{abstract}

Keywords: utility analysis; multiple utility; public transport; taxi service; GPS data

\section{Introduction}

In recent months, the coronavirus 2019-nCoV has spread all over the world, and many countries have taken emergency measures to counter the virus. For instance, the Chinese Government requested that Chinese people stay at home for at least two weeks. Although our occupied zones were limited temporarily to a large extent, such that we could not go to study or work, we continued fighting the coronavirus. In particular periods, overcoming the coronavirus and saving lives had the highest priority. Similarly, there are several priorities within public transport. Police cars have priority when they are chasing criminals, ambulances have priority when they are transferring patients, and fire engines have priority when they are travelling toward a fire. However, emergencies sometimes also occur in normal vehicles. For instance, a passenger might urgently take a taxi to the airport because his plane is taking off soon, or, a passenger might take a taxi to the hospital at midnight because of a sudden illness that requires urgent attention. It used to be almost impossible to arrange priorities for normal vehicles in an emergency. However, prioritization might be possible in the future with the 
rapid spread of the Internet of Things applications and the growing use of connected systems, such as Vehicle-to-Vehicle and Vehicle-to-Infrastructure.

There are various factors that affect public transport management, such as population, urban metrics, urban form, etc., and there are also some specific factors for sustainable transport management, such as energy, pollution, etc. However, the transportation utility values calculated by traditional utility methods are not comprehensive because traditional utility methods have been established within western economics, and their perspectives are limited to customers only. For instance, a passenger might arrive at their destination on time, but the taxi driver might not be able to eat dinner with his family. As a result, the passenger would benefit significantly from the trip, while the taxi driver would not, so the utility of the taxi driver would not be involved in traditional utility analyses. For another example, a taxi might drive on the road and pick up clients, but the pollution the taxi makes is harmful to the environment. As a result, the taxi driver will earn money from the trip while the environment becomes worse, so the utility of the environment would not be involved in traditional utility analyses. Thus, some objects and factors are ignored in traditional utility methods, and this narrow perspective is their primary drawback. In intelligent transportation systems, it is necessary to calculate transportation utility for promoting public traffic planning and management. To build a sustainable intelligent transportation system, modified utility methods are essential to analyze transportation utility in a comprehensive way with innovative technologies and efficient communication systems. To solve the disadvantages of traditional utility methods, it is necessary to establish a new method to build sustainable public transport in the future. In this study, a Multiple Utility Method and Transportation Utility Method are proposed for promoting public transport planning and management.

Hainan Province is the southernmost province of China, and Hainan Island is the second-largest island behind Taiwan Island in China. In recent years, several policies have promoted the sustainable development of Hainan. On the one hand, the Chinese Government attached great importance to the economic development of Hainan Province. In 2018, the Hainan Pilot Free Trade Zone was established to support the deepened reforms and opening up of Hainan Province. On the other hand, the Chinese Government paid great attention to the vehicle pollution problem of Hainan Island. All the taxis on Hainan Island must be updated to use clean energies by the end of 2020, and there should be more than 10,000 sharing vehicles in Hainan Province By the end of 2025. As the capital city of Hainan Province, Haikou City has been given an important task—building sustainable public transport. For sustainable transport planning and management, the road network infrastructure and the public transportations play key roles. In this study, the Transportation Utility Method was applied in Haikou City based on GPS-equipped taxi data.

The rest of this paper is organized as follows: Section 2 reviews related works; Section 3 introduces the formulas, models, data, and tools; Section 4 engages in a sample analysis; Section 5 applies the Transportation Utility Method in Haikou; Section 6 offers a discussion; and Section 7 summarizes the main conclusions, contributions and proposed future directions.

\section{Literature Review}

\subsection{Public Transportation}

Public Transport (PT) is one of the basic public services that the government provides for everyone. Increasing the use of PT is one of the most convenient strategies to alleviate the excessive use of private cars in most metropolitan areas, as introduced by Eboli et al. (2015) [1]. There are different forms of sustainable PT in our normal daily lives, such as buses [2], trams [3], subways [4], public bicycles [5], etc. With the rapid progress of transportation technologies, there are increasingly more advanced applications involved in comprehensive PT systems, such as maglev trains [6], high-speed rails [7], electric vehicles [8], driverless vehicles [9], customized vehicles [10], etc. Indeed, we could even 
imagine a future where we travel through cities in unmanned aerial vehicles [11]. In recent years, related works have focused on several potential topics, as follows:

(i) PT contributions. Some studies focused on the contributions of PT systems to our society. First, PT helps in reducing distances and travel times by providing greater efficiency. As a basic industry, the PT industry contributes to many other urban industries, such as urban tourism [12]. Choi et al. (2020) [13] confirmed the predominant complementary relationship between transportation and communication industries in six Asian countries and regions. Second, PT helps increase territorial cohesion. Since the middle of the last century, post-industrial cities around the world have been decreasing in population and shrinking due to a decline in their structural growth models, as introduced by Francisco et al. (2019) [14]. Balsa-Barreiro et al. (2019) [15] discussed how the territory tends to converge depending on the PT systems using time-distorted maps in a Spanish region. Third, PT systems are positively associated with economic competence. Pinna et al. (2017) [16] tested the correlations between the growth of smart mobility services and European and national financial investments based on the data of 22 Italian cities in the smart mobility sector, and the results showed that remarkable progress was made in the field of sustainable mobility, especially between 2010 and 2015. Frick et al. (2018) $[17,18]$ investigated the relationships between city size, urban concentration, and economic growth between 1980 and 2010 and proposed that small cities of up to 3 million inhabitants are more conducive to economic growth than big cities for a majority of countries and that urban concentration is beneficial for economic growth in high-income countries. These results highlight the positive link between PT systems and economic growth.

(ii) PT systems. Li et al. (2019) [19] proposed a method based on running timetables and position coordinates to analyze the vulnerabilities and critical areas of PT systems in China and indicated that economic development and population density are essential to PT system design. Saez et al. (2019) [20] proposed an assistance system based on radio frequency communication technologies for people with visual disabilities to facilitate their mobility in PT systems. Perera et al. (2020) [21] designed a lifecycle thinking-based multi-period PT infrastructure-planning framework to develop sustainable electric vehicles. Erdogan et al. (2020) [22] proposed a maintenance decision support approach for PT systems in Istanbul, particularly for rapid transit bus systems, to eliminate the risks arising from related failures. Macioszek et al. (2020) [23] examined the features associated with park and ride parking locations in Cracow and indicated that such park and ride systems are conducive to the development of PT in cities.

(iii) PT technologies. Bartlomiejczyk et al. (2018) [24] introduced smart grid technologies based on the practices in Gdynia and indicated that these technologies could save electric energy for PT systems. Thomä et al. (2019) [25] proposed a distributed multi-input-multi-output radar service based on 5G technology to support PT safety. Xylia et al. (2019) [26] introduced charging technologies based on the project experiences in the Nordic countries of the EU and indicated that these technologies could reduce the maintenance costs of PT infrastructure. Li et al. (2020) [27] estimated the jerk effect changes under two vehicle-to-vehicle communications based on experimental data and proposed a car-following model to improve traffic flow stability for PT systems. Sheikh et al. (2020) [28] proposed an automatic traffic incident detection technique based on vehicle to infrastructure communications to monitor PT scenarios.

(iv) PT data-driven approaches. Sun et al. (2016) [29] introduced an analytical framework to deal with high-dimensional human mobility data and applied it to a four-way dataset recording 14 million PT journeys extracted from smart card transactions in Singapore. Xu et al. (2018) [30] investigated the application of big data in autonomous vehicles and discussed three emerging issues related to the Internet of Vehicles (IoV) big data studies, including the IoV big data sourcing and preprocessing issue, the IoV network protocol issue, and the big-data-powered IoV service issue. Liu et al. (2018) [31] developed a bi-objective, bi-level integer programming model for PT timetable synchronization and proposed a sequential search method based on the deficit function. Antwi et al. (2020) [32] compared the traffic performance indicators between public transport and private transport based on a survey 
in Oforikrom and suggested that transport modes and travel time dynamics should be considered together. He et al. (2020) [33] estimated a PT crowding evaluation based on the smart card data of trams and buses in Europe and indicated that infrequent passengers ignore crowding when they make route choices. Tang et al. (2020) [34] proposed a hybrid method combining a fuzzy rough set and a fuzzy neural network for the imputation of missing traffic data, which can improve the data quality of PT data. Ghahramani et al. (2020) [35] reviewed and classified the methods and techniques to extract information from mobile phone data and discussed their pros and cons.

(v) PT reviews. Liu et al. (2017) [36] reviewed the development and application of deficit function modelling in PT and indicated that graphical deficit function concepts are conducive to PT planning and operations. Soest et al. (2020) [37] discussed how walking relates to the use of PT and indicated that further empirical research on the influences of culture and climate in different geographical areas is needed.

\subsection{Transportation Factor}

Since transportation is a complex system, there are many factors involved in transportation activities. In recent years, related works have included several potential topics, as follows:

(i) Passenger factors. Yang et al. (2019) [38] took human behaviours into consideration and discussed integrated designs for PT infrastructure and public spaces using current methods and tools. Shang et al. (2019) [39] took the passenger waiting cost into consideration and developed an extended vehicle scheduling model for PT planning and operations. Jiang et al. (2019) [40] proposed a PT content distribution system to improve the quality of the experience for passengers by decreasing access delays and costs of usage. Salonen et al. (2019) [41] investigated the real-life user experiences of a driverless shuttle bus based on a survey of 44 passengers who travelled a predefined route in a driverless shuttle bus and indicated that people are much more intolerant of accidents caused by autonomous vehicles than those caused by humans. Bosehans et al. (2020) [42] divided passengers into serval groups by their individual preferences based on goal framing theory and indicated that passengers have stable types based on a travel survey in England. Yap et al. (2020) [43] took crowding and feeling into consideration and estimated a discrete choice model based on smart card data, indicating that crowding has a significant effect on passengers' route choices in PT.

(ii) Driver factors. Virojboonkiate et al. (2019) [44] proposed a driver identification system based on acceleration sensor data for PT systems. Mokarami et al. (2019) [45] investigated 336 PT bus drivers in Tehran with two questionnaires and indicated that the organizational safety culture had positive effects on decreasing the unsafe behaviours of PT drivers and reducing PT accidents. Kang et al. (2019) [46] investigated 317 drivers in Malaysia online and indicated that it was necessary to develop interventions to meet the specific lifestyles and demands of PT drivers. Plano et al. (2020) [47] analyzed a stated choice survey administered to paratransit drivers in Cape Town and indicated that it was sustainable to engage in corporatization to improve PT services.

(iii) Economic factors. Algaba et al. (2019) [48] discussed horizontal cooperation in a multimodal PT system from the perspective of profit allocation and proposed an approach for PT companies based on game theory. Cigu et al. (2019) [49] estimated the interactions between PT infrastructure and economic performance in EU countries and ensured a significant internal impact. Pavon et al. (2019) [50] estimated the interactions of transport pricing, transport service provisions, and cost recovery under different funding schemes for PT infrastructure. Wang et al. (2020) [51] proposed a multi-agent deep reinforcement learning framework with dynamic and flexible holding planning strategies to improve the efficiency of PT services by avoiding bunching. Wołek et al. (2020) [52] explored the factors that influenced the development of the trolleybus system based on a case study in Gdynia and Sopot and indicated that trolleybus transport is economically efficient after including external costs into the economic calculations.

(iv) Safety factors. Guo et al. (2016) [53] tested the functions of parallelogram-shaped pavement markings based on an experiment, and the results showed that the use of parallelogram-shaped 
pavement markings helped in reducing both the frequency and severity of crashes at pedestrian crosswalks by reducing the proportion of drivers exceeding the speed limit by an average of $11.03 \%$. Pinna et al. (2018) [54] proposed that the least considered among all pedestrian characteristics is speed. Guido et al. (2019) [55] investigated the correlation between real accident locations and simulated risk areas in Cosenza based on a microscopic framework and indicated that traffic conflict techniques had a positive effect on improving PT safety. Chowdhury (2019) [56] investigated decision differences between male drivers and female drivers based on a survey in Auckland, Wellington, and Christchurch and indicated that women were sensitive to waiting times and $30 \%$ more likely than men to save time through PT transferring. Chowdhury et al. (2020) [57] investigated the safety needs of female riders at PT terminals based on an online survey in Auckland and indicated that mobile phones and headphones helped female riders feel safer.

(v) Environmental factors. Nesheli et al. (2017) [58] investigated the benefits of using real-time PT operational tactics and indicated that greener PT systems help in reducing greenhouse gas emissions. Duran-Micco et al. (2019) [59] compared several experiments on PT vehicles and proposed a memetic algorithm to minimize both total travel time and CO2 emissions. Cuthill et al. (2019) [60] investigated a light-rail system in London using quantitative methods and indicated that the physical properties of PT infrastructure and the non-physical attributes of society could help individuals to succeed when combined. Ko et al. (2019) [61] took environmental aspects into consideration and proposed a mathematical analysis of the environmental factors of forming a platoon of smart vehicles.

\subsection{Taxi Service Improvement}

Taxis are the main constituent of the urban PT system. Ideal PT services carry passengers directly between their origins and destinations, as argued by Paulley et al. (2005) [62]. Due to the advantages of their flexibility, taxis always provide ideal PT services for passengers with no transfers. In recent years, related works have included several potential topics, as follows:

(i) Taxi origin and destination distribution estimations. The Origin and Destination (OD) of taxis can be extracted by GPS-equipped taxi data. Taxi GPS trajectory data contain massive spatial and temporal information on urban human activities and mobility, as introduced by Tang et al. (2015) [63]. Zhan et al. (2013) [64] proposed a descriptive model for estimating the hourly average of urban link travel times using taxicab OD trip data. Kan et al. (2019) [65] proposed a method to detect traffic congestion based on the GPS trajectories of taxis at a fine-grained level and applied it to a road intersection in Wuhan. Zhang et al. (2020) [66] proposed a data-driven ensemble learning method based on the support vector regression model and deep learning model to predict taxi destinations.

(ii) Taxi demand estimations and predictions. Tang et al. (2019) [67] investigated the characteristics of travel demand and the related variables based on taxi GPS trajectories in New York and indicated that most taxi trips are concentrated in only a fraction of the geographical area. Sun et al. (2020) [68] investigated the impact of rainfall on taxi operations and indicated that rainfall is more effective in dispatching taxis to high demand regions than providing more taxis. Liu et al. (2020) [69] estimated the correlation between taxi demand, socio-economic factors, transport systems, and land-use patterns based on taxi data in Qingdao and indicated that there are high taxi demands in commercial areas and public service areas.

(iii) Passenger care. Improving customer satisfaction and reducing operational costs are two key factors by which transit authorities enhance passenger care, as introduced by Ma et al. (2014) [70]. Wong et al. (2019) [71] investigated the market potential of operating premium electric taxis in the dispatching mode in Hong Kong and indicated that the walking time to taxis and the waiting time for taxis are the most critical concerns for passengers. Tang et al. (2020) [72] proposed a model to analyze the route choice behaviour of taxi drivers for determining the next passenger in the urban road network. Askari et al. (2020) [73] estimated the main factors of passengers' perceptions of fixed-route taxi services in Shiraz and indicated that the behaviour of taxi drivers is the strongest factor. 
(iv) Intelligent algorithm applications. To solve route planning problems with big data, intelligent algorithms such as neural networks [74] are beneficial for finding patterns and features. Ghahramani et al. (2019) [75] proposed an exploratory spatial data analysis algorithm for urban planning and development. Dai et al. (2019) [76] proposed a path travel time model for buses considering the link travel time and station dwell time and applied it to a bus line in Hangzhou. Huang et al. (2020) proposed an integrated imputation algorithm based on fuzzy C-means and the genetic algorithm and applied it to GPS-equipped taxi data in Manhattan to improve the accuracy of the estimated values.

(v) Taxi reviews. Poó et al. (2018) [77] reviewed the working conditions of taxi drivers, their relationship to road risk exposure, and their consequences on the health of workers, indicating that it is necessary for taxi drivers to pay more attention to their health. Skok et al. (2019) [78] reviewed the taxi literature and private hire industry in London and identified six key research themes, including disruptive innovation, the sharing economy, business models, historical context, regulations, and labour.

\subsection{Utility Analysis Method}

Utility is a classic economic concept proposed by western economists. Bentham (1780) [79] proposed the concept of utilitarianism, which is regarded as the source of traditional utility theory. Jevons (1871) [80], Menger (1871) [81], and Walras (1874) [82] proposed a declining law of marginal utility, which was regarded as a marginal revolution. Marshall (1890) [83] proposed the equilibrium price theory, which is regarded as one of the foundations of modern economics. Neumann et al. (1944) [84] applied game theory to economics and described the individual decision-making process according to expected utility functions, which is regarded as the Neumann-Morgenstern utility theorem. Arrow et al. (1954) [85] proved the existence of equilibrium prices when commodities are divisible and utility functions are concave, which is regarded as an analytical paradigm for dealing with uncertain decision-making problems. According to traditional utility theory, utility can be defined by Formula (1):

$$
u(x, y)
$$

where $u$ represents the utility of the customer, $x$ represents the consumption of the first commodity, and $y$ represents the consumption of the second commodity.

In recent years, traditional utility theory has been applied in various fields of transportation, including autonomous vehicles, electric vehicles, and bicycles, which are described as follows:

(i) Calculations based on utility theory. Kalan et al. (2019) [86] tested the strength of multiplicative functional forms for the prioritization of maintenance activities in bridges based on multi-attribute utility theory. Francis et al. (2019) [87] interviewed representatives from 29 departments of transportation and five consultancies in the United States and estimated the cost and utility for statewide travel in Kentucky. Cantelmo et al. (2019) [88] calculated the utility lost due to traffic congestion based on a set of properties and proposed a utility function for modelling activities with different durations.

(ii) New methods for utility analyses. Bigazzi et al. (2019) [89] proposed a utility-based behavioural model of bicycle speed choice based on travel time, energy expenditure, and control factors. Hasnine et al. (2019) [90] proposed a random utility-based measure of accessibility to explain the first-mile issue in urban transit and indicated that conventional measures tend to over-estimate access to transit. Li et al. (2019) [91] proposed a new location design problem to maximize the total weighted benefits between users and multiple services and indicated that a more distance-dependent utility measure and a higher concentration of users help achieve better total utility.

(iii) Comparisons among various utility models. Sharma et al. (2019) [92] compared the park-and-ride lot choice behaviour of users based on the random utility maximization model and random regret minimization model and indicated a trade-off relationship. Khan et al. (2019) [93] compared the solution qualities and computation times of 12 global mixed-integer non-linear programming solvers and proposed a wireless charging utility maximization framework for electric 
vehicles. Bachmann (2019) [94] calculated the impact of changes in transport networks and spatial economies on interregional and international trade patterns based on two models.

(iv) Intelligent algorithms for utility improvement. Xia et al. (2019) [95] proposed a time-averaged stochastic gradient routing algorithm to maximize the utilization of limited network resources. Luo et al. (2019) [96] proposed a service priority-oriented spectrum allocation scheme in the LTE-V network to optimize the utility of vehicles. Goebel et al. (2019) [97] estimated utility factors based on a data set of 1768 individual Chevrolet Volt plug-in hybrid electric vehicles and indicated that machine learning techniques have higher accuracy than simple simulations.

(v) Utility reviews. Singleton (2019) [98] discussed the positive utility of autonomous vehicles and indicated that further empirical research on the experiential, time use, and travel time-saving impacts of autonomous vehicles is needed. Bukhsh et al. (2020) [99] discussed multi-year maintenance plans for bridges based on multi-attribute utility theory and proposed a comprehensive framework.

\subsection{Summary of Literature Review}

To sum up, some helpful works have already been done, which are described as follows.

(i) In terms of the public transportation field, many related works have made great progress using PT systems, PT technologies, and PT data-driven approaches. However, few of these studies analyzed PT problems via the utility analysis method.

(ii) In terms of the transportation factor field, related studies are considered from the perspectives of passengers, drivers, the economy, safety, and the environment.

However, few studies considered these factors from multiple perspectives or combined them.

(iii) In terms of the taxi service improvement field, most studies were performed from the perspective of passengers. Some studies proposed intelligent algorithms to detect traffic congestion and predict taxi destinations. However, few studies focused on taxi drivers, taxis, or the environment.

(iv) In terms of the utility analysis method field, traditional utility theory has been applied in various areas of transportation, such as the first-mile issue in urban transit, park-and-ride lot choice behaviour, multi-year maintenance plans for bridges, etc. Moreover, some studies proposed intelligent algorithms for utility improvement. However, few of them related utility to the trip's purpose. The priority given to travel varies with the utility of the trip's purpose, as noted by Moran et al. (1975) [100]. Furthermore, few of them calculated transportation utility from multiple perspectives.

Thus, it is necessary to develop a utility analysis method and apply it to GPS-equipped taxi data to develop better PT systems.

In our previous studies [101,102], we proposed management optimization for taxis and a Modified Digital Elevation model for vehicle movement analyses considering altitude (see Section 3.4). On the basis of these models, it is now possible for us to analyze transportation utility based on GPS-equipped taxi data.

How can we analyze transportation utility from multiple perspectives? How can we improve taxi services based on multiple utility analyses? In the next section, various methods and data are used to explore these questions.

\section{Methods and Materials}

\subsection{Analysis Procedure}

To solve these problems, a series of analysis procedures were established (see Figure 1). 


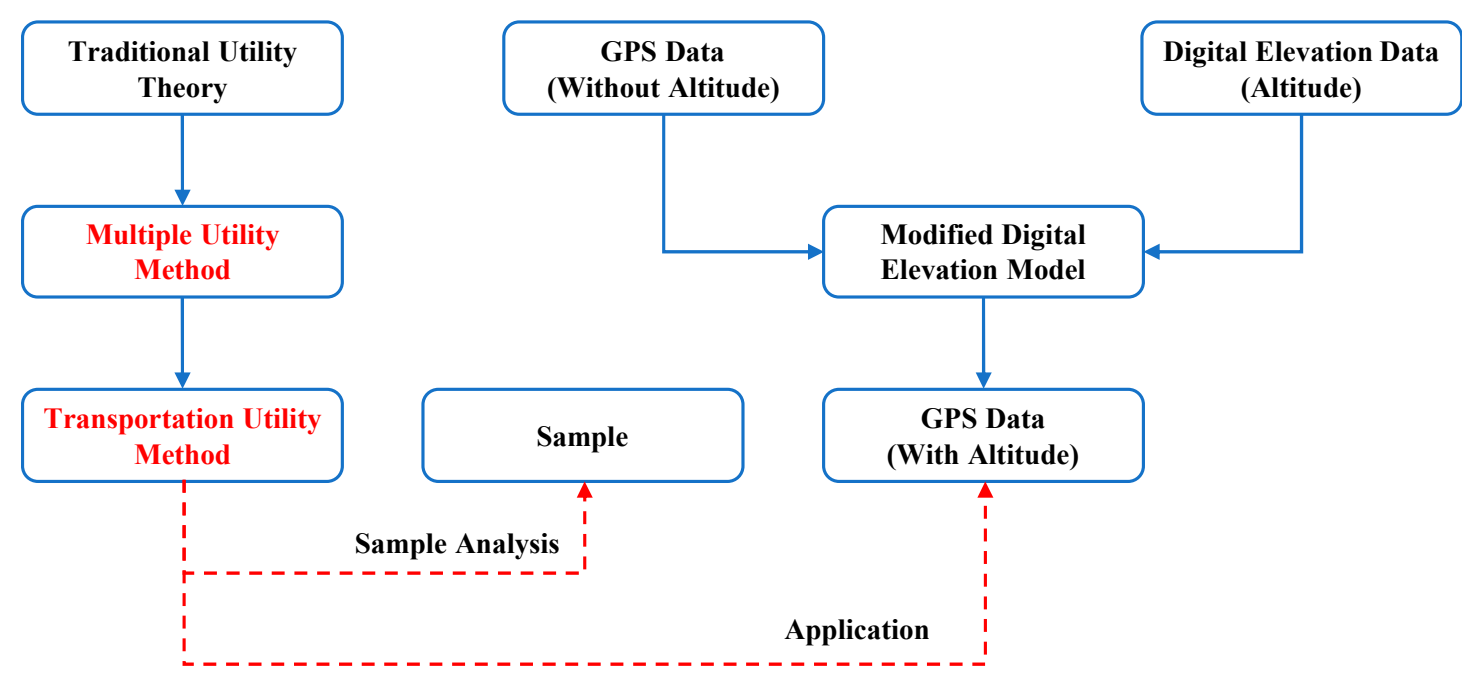

Figure 1. Analysis procedure design.

In Figure 1, the text in red represents the research points of this article.

In this model, the Multiple Utility Method is proposed based on traditional utility theory, and then the Transportation Utility Method is proposed based on the Multiple Utility Method.

In terms of data, GPS data without altitude and digital elevation data were collected first, and then GPS data with altitude were calculated based on the Modified Digital Elevation model.

The Transportation Utility Method was adopted for analyzing comprehensive public transport planning and operations, including a sample analysis (see Section 4) and an application based on GPS-equipped taxi data in Haikou (see Section 5).

The notations for the formulas are included in the Appendix A (see Table A1 in Appendix A).

\subsection{Multiple Utility Method}

The Multiple Utility Method calculates utility from multiple perspectives and takes various participants into consideration. Under traditional utility theory, the object refers to the customer, and the relationship between subject and object is straightforward (see Figure 2). In the Multiple Utility Method, the object could be the customer, commodity, or even the environment. Moreover, every subject could have multiple uses for multiple objects (see Figure 3). At the same time, multiple subjects could have multiple uses for the same object in return (see Figure 4).

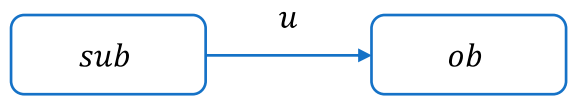

Figure 2. Schematic diagram of the relationship between subject and object under traditional utility theory.

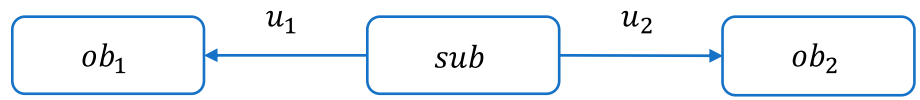

Figure 3. Schematic diagram of the relationship between one subject and multiple objects in Multiple Utility Method.

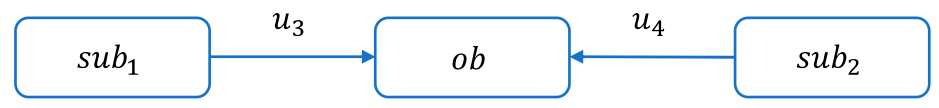

Figure 4. Schematic diagram of the relationship between multiple subjects and one object in Multiple Utility Method.

There are 3 steps in this section. 
(i) Defining the value. To calculate the values, the essential variables are expanded upon in Formula (1), and the basic function is established in Formula (2):

$$
v_{c}(z)
$$

where $v$ represents the value, $c$ represents the factor, and $z$ represents the participant to be analyzed (which can be the subject or the object, $z=s u b_{i}$ or $z=o b_{j}$ ). Formula (2) can then be converted into Formulas (3) and (4):

$$
\begin{gathered}
v\left(s u b_{i}\left(c_{k}\right)\right) \\
v\left(o b_{j}\left(c_{l}\right)\right)
\end{gathered}
$$

where $s u b$ represents the subject, $o b$ represents the object, and $i, j, k, l$ are serial numbers with no meaning.

The participant might have several values in various factors. The total value of the participant consists of all the individual values of the participant considering various factors, which can be calculated by Formula (5):

$$
V_{c}(z)=\sum v_{\mathcal{c}}(z)
$$

where $V$ represents the total value. Formula (5) can then be converted into Formulas (6) and (7):

$$
\begin{aligned}
V\left(s u b_{i}\right) & =\sum_{k=1}^{n} v\left(s u b_{i}\left(c_{k}\right)\right) \\
V\left(o b_{j}\right) & =\sum_{l=1}^{n} v\left(o b_{j}\left(c_{l}\right)\right)
\end{aligned}
$$

As a result, the individual values in various factors and the total value under the Multiple Utility Method are defined.

(ii) Defining the utility. To calculate utility from multiple perspectives, the essential variables were adopted as in Formula (2), and the basic function was established in Formula (8):

$$
u_{c}\left(s u b_{i}, o b_{j}\right)
$$

Formula (8) can be converted into Formula (9) as its complete format, and the relationship between Formulas (1) and (9) can be represented by Formula (10):

$$
\begin{gathered}
u\left(\operatorname{sub}_{i}\left(c_{k}\right), o b_{j}\left(c_{l}\right)\right) \\
\left\{\begin{array}{c}
x=s u b_{i}\left(c_{k}\right) \\
y=o b_{j}\left(c_{l}\right)
\end{array}\right.
\end{gathered}
$$

As a result, the utility under Multiple Utility Method is defined.

(iii) Connecting utility with value. In the Multiple Utility Method, the utility of $s u b_{i}$ for $o b_{j}$ depends on the extent to which $s u b_{i}$ has an effect on $o b_{j}$. This relationship can be represented by Formula (11):

$$
u_{c}\left(s u b_{i}, o b_{j}\right)=-\frac{v_{c}\left(o b_{j}\right)}{v_{c}\left(s u b_{i}\right)}
$$

Formula (11) can then be converted into Formula (12):

$$
u\left(s u b_{i}\left(c_{k}\right), o b_{j}\left(c_{l}\right)\right)=-\frac{v\left(o b_{j}\left(c_{l}\right)\right)}{v\left(s u b_{i}\left(c_{k}\right)\right)}
$$


As a result, the utility under the Multiple Utility Method can be calculated according to the value determined under the Multiple Utility Method.

Compared with traditional utility theory, there are more variables in the Multiple Utility Method. Three more variables $s u b, o b$, and $c$ were adopted to define the subjects and objects involved in the research, as well as their specific factors.

\subsection{Transportation Utility Method}

The transportation Utility Method was established based on the Multiple Utility Method. First, one of the most important features of transportation is that spacetime always changes (see Figure 5).

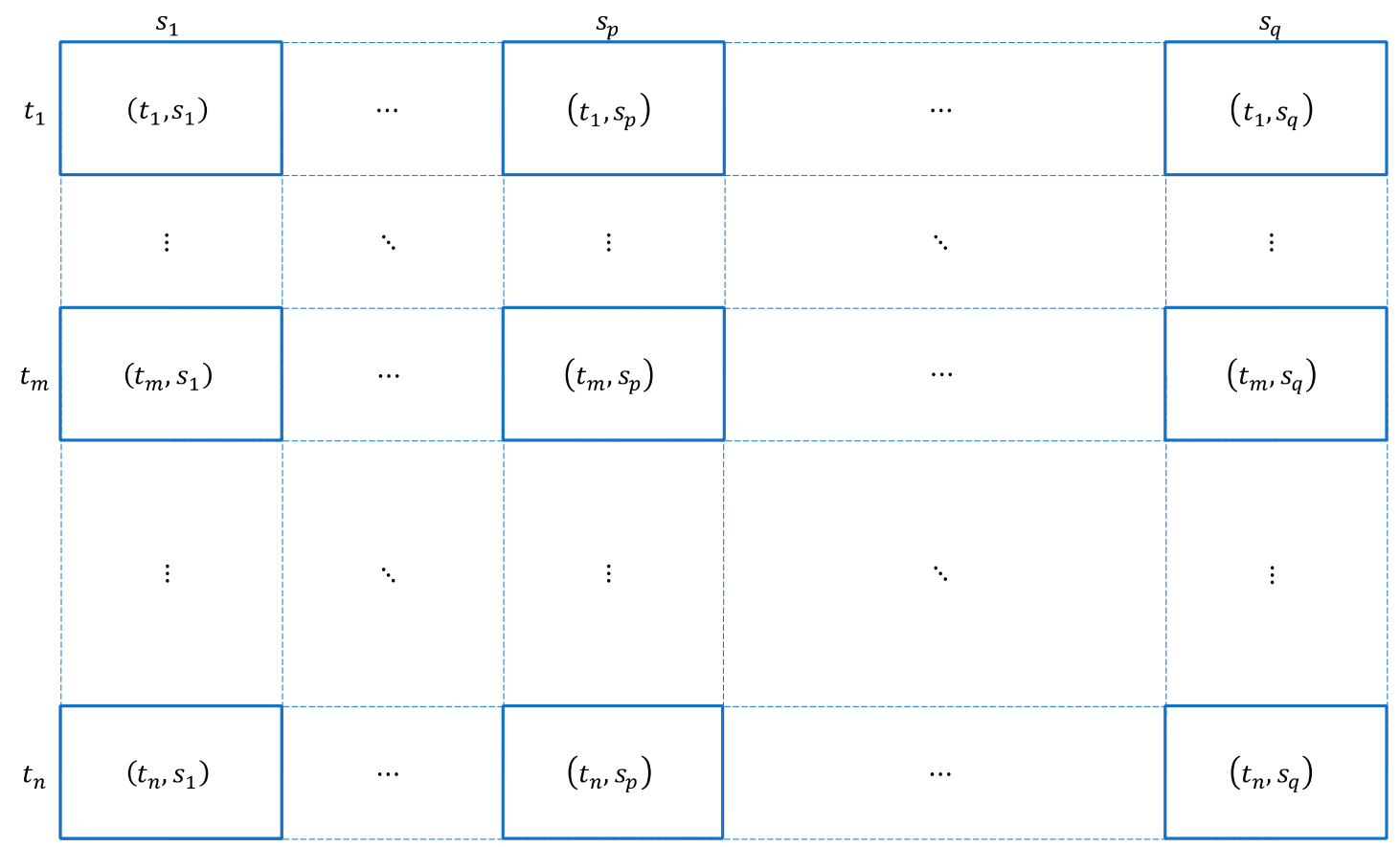

Figure 5. Schematic diagram of spacetime changes.

In Figure 5, every solid rectangle represents an individual point in spacetime, where $t$ represents time, and s represents space. The participant at spacetime $\left(t_{1}, s_{1}\right)$ might move to $\left(t_{n}, s_{1}\right),\left(t_{n}, s_{p}\right),\left(t_{n}, s_{q}\right)$, or other spacetimes as time passes. The participants in various spacetimes might also have different values. Thus, the Transportation Utility Method considers both space and time based on the Multiple Utility Method.

There are 4 steps in this section.

(i) Defining the value. To calculate the values, the essential variables were expanded upon in Formula (2), and the basic function was established in Formula (13):

$$
v_{t, s, c}(z)
$$

From the Multiple Utility Method, variables $t$ and $s$ are adopted here to calculate the values in the Transportation Utility Method. $v$ represents the value, $t$ represents the time, $s$ represents the space, and $c$ represents the factor. Further, $z$ represents the participant to be analyzed, which can be the subject or the object; in other words, $z=s u b_{i}$ or $z=o b_{j}$. Formula (13) can then be converted into Formulas (14) and (15):

$$
\begin{gathered}
v\left(s u b_{i_{t_{m}, s p}}\left(c_{k}\right)\right) \\
v\left(o b_{j_{t_{m}, s p}}\left(c_{l}\right)\right)
\end{gathered}
$$


where $s u b$ represents the subject; $o b$ represents the object; and $i, j, k, l, m, p$ are serial numbers with no meaning. The total value of the participant consists of all the individual values of the participant based on various factors, which can be calculated by Formula (16):

$$
V_{t, s, c}(z)=\sum v_{t, s, c}(z)
$$

where $V$ represents the total value. Formula (16) can then be converted into Formulas (17) and (18):

$$
\begin{aligned}
V\left(s u b_{i}\right) & =\sum_{k=1}^{n} v\left(s u b_{i_{t_{m}, s p}}\left(c_{k}\right)\right) \\
V\left(o b_{j}\right) & =\sum_{l=1}^{n} v\left(o b_{j_{t_{m}, s p}}\left(c_{l}\right)\right)
\end{aligned}
$$

As a result, individual values in various factors and the total value under the Transportation Utility Method are defined.

(ii) Defining the utility. To calculate the utility from multiple perspectives, essential variables were adopted as in Formula (13), and the basic function was established in Formula (19):

$$
u_{t, s, c}\left(s u b_{i}, o b_{j}\right)
$$

Formula (19) can be converted into Formula (20), and the relationship between Formulas (1) and (20) can be presented by Formula (21):

$$
\begin{gathered}
u\left(s u b_{i_{t_{m}, s_{p}}}\left(c_{k}\right), o b_{j_{t_{m}, s p}}\left(c_{l}\right)\right) \\
\left\{\begin{array}{c}
x=s u b_{i_{m, s p},}\left(c_{k}\right) \\
y=o b_{j_{m, s p}}\left(c_{l}\right)
\end{array}\right.
\end{gathered}
$$

As a result, the utility under the Transportation Utility Method is defined.

(iii) Connecting the utility with the value. In the Transportation Utility Method, the utility of $s u b_{i_{t_{m, s p}}}$ for $o b_{j_{t_{m}, s_{p}}}$ depends on the extent to which $s u b_{i_{t_{m}, s_{p}}}$ has an effect on $o b_{j_{t_{m}, s_{p}}}$. This relationship can be presented by Formula (22):

$$
u_{c}\left(s u b_{i_{t_{m}, s_{p}}}, o b_{j_{t_{m}, s_{p}}}\right)=-\frac{v_{c}\left(o b_{j_{t_{m}, s_{p}}}\right)}{v_{c}\left(s u b_{i_{t_{m}, s_{p}}}\right)}
$$

Formula (22) can then be converted into Formula (23):

$$
u\left(s u b_{i_{t_{m}, s p}}\left(c_{k}\right), o b_{j_{t_{m}, s p}}\left(c_{l}\right)\right)=-\frac{v\left(o b_{j_{t_{m}, s_{p}}}\left(c_{l}\right)\right)}{v\left(s u b_{i_{t_{m}, s_{p}}}\left(c_{k}\right)\right)}
$$

As a result, the utility under the Transportation Utility Method can be calculated by the value under the Transportation Utility Method.

(iv) Taking time periods into consideration. There is a situation particular to the Transportation Utility Method. The values of participants are sometimes continuous instead of dispersed. For instance, taxi drivers may feel tired while driving their taxis instead of feeling tired suddenly at the arrival position. Suppose that there is a subject moving from spacetime $\left(t_{1}, s_{1}\right)$ to spacetime $\left(t_{n}, s_{q}\right)$ and that 
the subject's value of the specific factor $c_{k}$ is continuous; then, the individual value of the subject during the time period $t_{1} \sim t_{n}$ can be calculated by Formula (24):

$$
v\left(s u b_{i_{t_{1} \sim t_{n}, s_{1} \sim s_{q}}}\left(c_{k}\right)\right)=\sum_{m=1}^{n} \sum_{p=1}^{q} v\left(s u b_{i_{t_{m}, s_{p}}}\left(c_{k}\right)\right)
$$

In the same way, the individual value of the object during the time period $t_{1} \sim t_{n}$ can be calculated by Formula (25):

$$
v\left(o b_{j_{t_{1} \sim t_{n}, s_{1} \sim s_{q}}}\left(c_{l}\right)\right)=\sum_{m=1}^{n} \sum_{p=1}^{q} v\left(o b_{j_{t_{m}, s_{p}}}\left(c_{l}\right)\right)
$$

Moreover, the total value of the subject during the time period $t_{1} \sim t_{n}$ can be calculated by Formula (26). The total value of the object during the time period $t_{1} \sim t_{n}$ can be calculated by Formula (27):

$$
\begin{aligned}
V\left(s u b_{i_{t_{1} \sim t_{n}, s_{1} \sim s_{q}}}\right) & =\sum_{m=1}^{n} \sum_{p=1}^{q} V\left(s u b_{i_{t_{m}, s_{p}}}\right) \\
V\left(o b_{j_{t_{1} \sim t_{n}, s_{1} \sim s_{q}}}\right) & =\sum_{m=1}^{n} \sum_{p=1}^{q} V\left(o b_{j_{t_{m}, s_{p}}}\right)
\end{aligned}
$$

Furthermore, the utility of $s u b_{i_{t_{m}, s p}}$ for $o b_{j_{t_{m}, s p}}$ during the time period $t_{1} \sim t_{n}$ can be calculated by Formula (28):

$$
u\left(s u b_{i_{1} \sim \tau_{n}, s_{1} \sim s_{q}}\left(c_{k}\right), o b_{j_{t_{1} \sim t_{n}, s_{1} \sim s_{q}}}\left(c_{l}\right)\right)=-\frac{v\left(o b_{j_{t_{1} \sim t_{n}, s_{1} \sim s_{q}}}\left(c_{l}\right)\right)}{v\left(s u b_{i_{t_{1} \sim \tau_{n}, s_{1} \sim s_{q}}}\left(c_{k}\right)\right)}
$$

As a result, the utility can be calculated by the value under the Multiple Utility Method, even for different time periods.

Compared to traditional utility theory, there are more variables in the Transportation Utility Method. Five more variables $s u b, o b, t, s$, and $c$ were adopted to define the subjects and objects involved in this research and their specific factors. Moreover, it is possible to calculate utility based on time periods that the traditional utility method cannot solve.

\subsection{Vehicle Movement Calculation Method}

Location and distance are two essential pieces of information in transportation studies. To describe the location of vehicles in a mathematical way, the polar coordinate system is established in Formula (29):

$$
P(\rho, \theta, \varphi)
$$

where $\rho \geq 0,0 \leq \theta \leq \pi$, and $0 \leq \varphi<2 \pi$. Here, $\rho$ represents the radial distance, $\theta$ represents the polar angle, and $\varphi$ represents the azimuthal angle.

Suppose that there is a taxi moving from spacetime $\left(t_{m}, s_{p}\right)$ to spacetime $\left(t_{n}, s_{q}\right)$. Its time changes from $t_{m}$ to $t_{n}$, and its space changes from $s_{p}$ to $s_{q}$.

The original distance model was established in our previous study (2018) [101]. This model was adopted to calculate movements based on GPS data without altitude. Based on GPS data without altitude, the distance between $s_{p}\left(R, \theta_{p}, \varphi_{p}\right)$ and $s_{q}\left(R, \theta_{q}, \varphi_{q}\right)$ can be calculated by Formula (30):

$$
d\left(s_{p}, s_{q}\right)=\operatorname{Rarccos}\left(\sin \theta_{p} \sin \theta_{q} \cos \left(\varphi_{q}-\varphi_{p}\right)+\cos \theta_{p} \cos \theta_{q}\right)
$$

A Modified Digital Elevation model was established in our previous study (2020) [102]. This model was adopted to calculate GPS data with altitude based on GPS data without altitude and digital elevation 
data. Based on GPS data with altitude, the distance between $s_{p}\left(R+h_{p}, \theta_{p}, \varphi_{p}\right)$ and $s_{q}\left(R+h_{q}, \theta_{q}, \varphi_{q}\right)$ can be calculated based on the Modified Digital Elevation model using Formula (31):

$$
d^{\prime}\left(s_{p}, s_{q}\right)=\sqrt{\left[\left[\left(R+\frac{h_{p}+h_{q}}{2}\right) \arccos \left(\sin \theta_{p} \sin \theta_{q} \cos \left(\varphi_{q}-\varphi_{p}\right)+\cos \theta_{p} \cos \theta_{q}\right)\right]^{2}+\left(h_{q}-h_{p}\right)^{2}\right.}
$$

where $R=6378.1370(\mathrm{~km})$, which represents the radius of the earth. In other words, the distance between two locations of taxis can be calculated approximately using GPS data with altitude and the radius of the earth.

Furthermore, the average speeds of taxis can be calculated by Formula (32):

$$
\bar{v}=\frac{\Delta D}{\Delta T}=\frac{d^{\prime}\left(s_{p}, s_{q}\right)}{t_{n}-t_{m}}
$$

where $\bar{v}$ represents the average speed, $D$ represents the distance, and $T$ represents the time. Moreover, $\Delta D$ represents the distance change, and $\Delta T$ represents the time change. The Modified Digital Elevation model is adopted in this paper to calculate vehicle movements. In detail, GPS data without altitude and digital elevation data were collected and converted into GPS data with the altitude based on the Modified Digital Elevation model.

In this paper, vehicle movements were calculated by Formula (31), while vehicle speeds were calculated by Formula (32).

\subsection{Data and Tools}

(i) Data Source. Data in this study were provided by the big data platform, Didi Chuxing GAIA Initiative, which was developed by the company Didi Chuxing, one of the leading mobile transportation platforms in China (see Data Availability). The GPS data for taxis in this study were collected from Haikou City in Hainan Province of China. Major data items include the order ID, longitude, latitude, and time. Map data were collected from Google Maps.

(ii) Data Processing. According to the original data, all the taxi orders in Haikou were recorded from 00:00 a.m. to 11:59 p.m. on 1 May 2017, producing 70,044 records. Afterwards, flawed data were removed to ensure the integrity of the data. As a result, there were 69,174 records retained in the processed data. In this research, the coordinate system was the World Geodetic System 1984.

For the border point extraction, there were 6 steps:

1. The original map with altitude information was imported by ArcGIS.

2. The border line was extracted by the 3D analyst tool called Raster Domain.

3. The border line was converted into border points using the data management tool called Feature Vertices to Points.

4. Two new fields named Longitude and Latitude were added into the attribute table of the border points.

5. The longitudes and latitudes of border points were extracted from the ArcGIS geodatabase using the attribute table tool called Calculate Geometry Attributes.

6. The GPS data of the border points were converted into a Microsoft Excel file using the conversion tool called Table to Excel.

As a result, the border points were prepared.

For digital elevation data processing, there are 4 steps:

1. The original digital elevation data were imported using ArcGIS.

2. GPS data without altitude in a Microsoft Excel file were converted into an XY table in the ArcGIS geodatabase using the conversion tool called Excel to Table. 
3. The XY table was adopted to create a point feature class using the data management tool called XY Table to Point.

4. The altitude data of the point feature class was extracted by the spatial analyst tool called Extract Values to Points.

As a result, GPS data with altitude were prepared (see the file named "Data.xlsx" in the Supplementary Materials).

(iii) Implement Tools. Several types of statistics software were adopted in this study. Microsoft Office 16.35 was applied for the original data processing, result storage and flowchart drawing. Matlab R2020a (trial version) was applied for the programming. Rivermap X3.1 was applied to extract the altitude from digital elevation data. ArcGIS Pro 2.5.0 (trial version) was used for extracting and processing the geodata of the tracking points and border points, including the longitude, latitude, and altitude. Stata SE 15.1 (trial version) was used for the statistical analyses and statistical map drawing. Global Mapper 21.1 (trial version) was used for real map drawing.

\section{Sample Analysis}

\subsection{Sample Set}

There are three parts in this section.

(i) Sample introduction. In the sample, a scenario was designed where a passenger is moving from his home to the airport by taxi. The passenger must arrive at the airport on time, or he will miss his flight. The scenario was converted into a schematic diagram (see Figure 6), and the notations for the signs in the sample are included in the Appendix A (see Figure A1 in Appendix A).

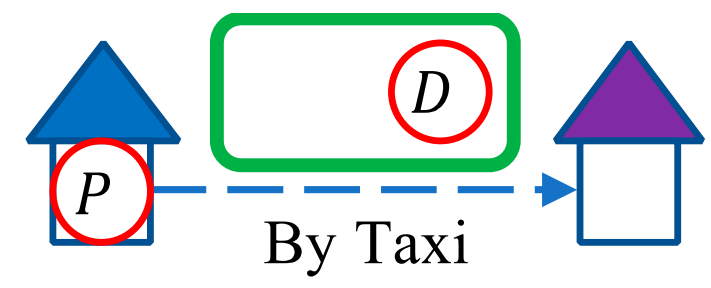

Figure 6. Schematic diagram of the sample.

In Figure 6, there are six notations for legends in the sample

- The blue triangle represents the departure position.

- The purple triangle represents the arrival position.

- The red circle with a letter $P$ inside represents the passenger.

- The red circle with a letter $\mathrm{D}$ inside represents the taxi driver.

- The green ellipse with a stick below represents a tree.

- $\quad$ The green block represents the taxi.

Before the trip, only the driver was inside the taxi. During the drip, both the driver and a passenger were in the taxi. After the trip, the passenger left the taxi, and the driver obtained money from the passenger as a fare. The spacetime of the sample changes is shown in Figure 7. 


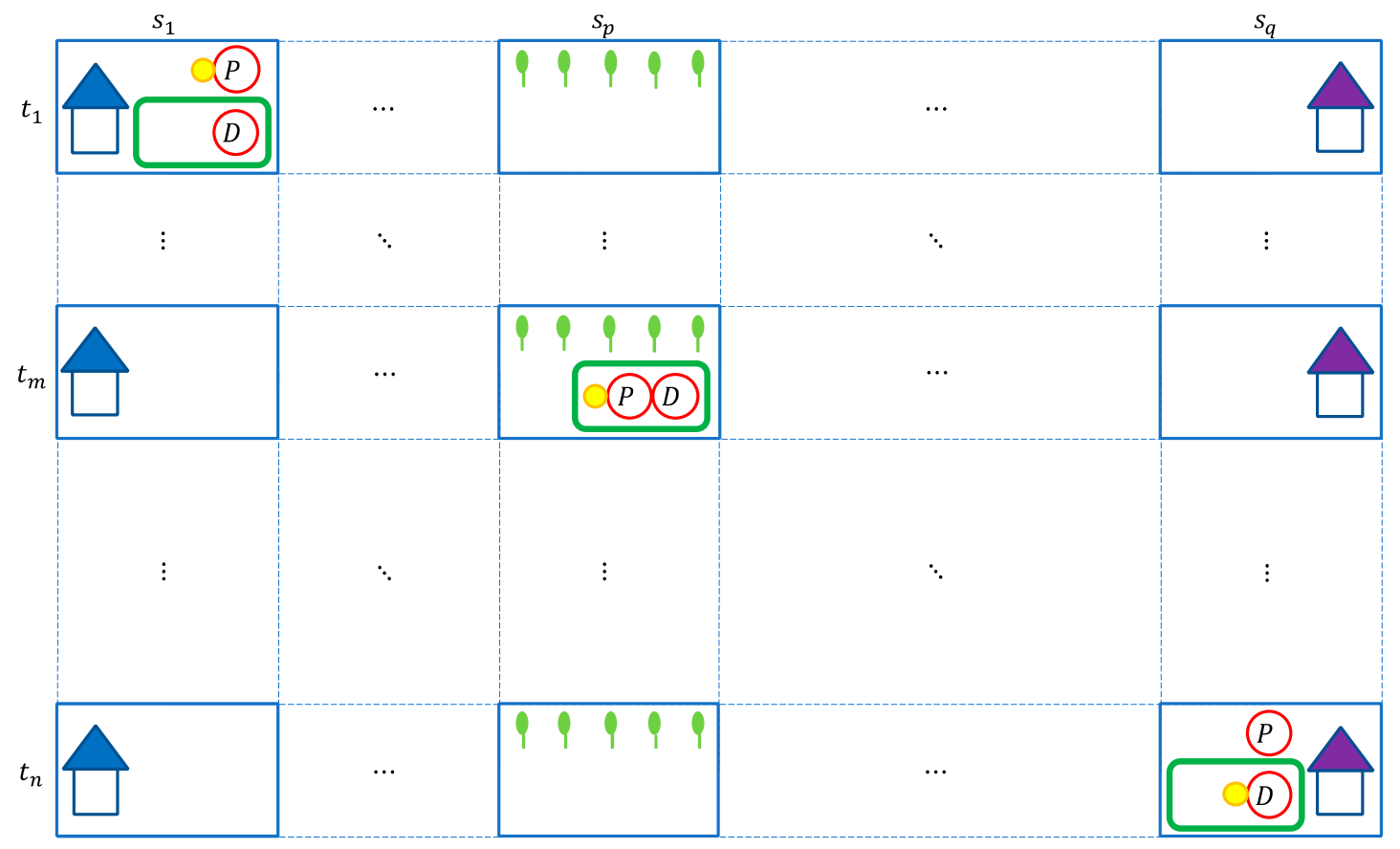

Figure 7. Space and time changes in the sample.

In Figure 7, six notations were mentioned previously, with two more notations used in the sample.

- The yellow circle represents the money the passenger paid to the taxi driver for the trip.

- The green ellipse with a stick below represents a tree.

In Figure $7, n>1$ and $q>1$. First, in spacetime $\left(t_{1}, s_{1}\right)$, the passenger and the taxi driver are at the departure position. In detail, the taxi driver picks the passenger up at spacetime $\left(t_{1}, s_{1}\right)$, and both are together in the taxi from then on. Second, at spacetime $\left(t_{m}, s_{p}\right)$, both are travelling to the arrival position using the taxi. In detail, there are some trees along the way, and the taxi's pollution might be harmful to those trees. Third, at spacetime $\left(t_{n}, s_{q}\right)$, both the driver and passenger are at the arrival position. Further, the passenger paid money to the taxi driver at the arrival position at spacetime $\left(t_{n}, s_{q}\right)$. The Transportation Utility Method takes both space and time into consideration.

(ii) Sample relationships. In the sample, there are four subjects (see Figure 8).

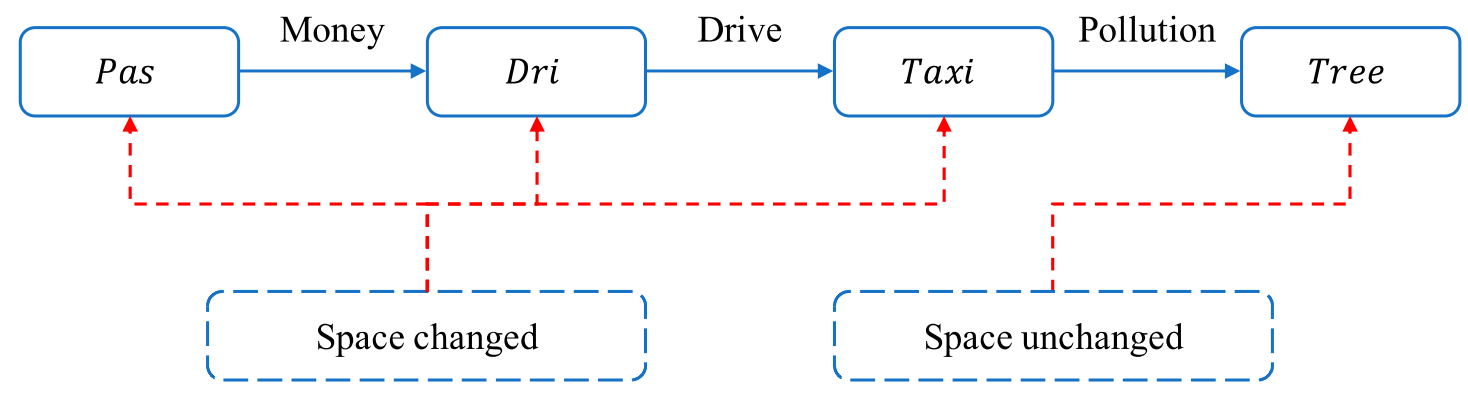

Figure 8. Main relationships among 4 subjects in the sample.

In Figure 8, there are four notations for the symbols in the sample:

- The symbol Pas represents the passenger.

- $\quad$ The symbol Dri represents the taxi driver.

- The symbol Taxi represents the taxi.

- The symbol Tree represents the environment. 
There were, moreover, three main relationships among these four subjects:

1. The passenger paid money to the driver.

2. The taxi driver drove the taxi.

3. Taxi output pollution into the environment.

During these procedures, the spaces of the passenger, taxi driver, and taxi changed, while the spaces of the trees remained unchanged.

(iii) Sample value set. There are four main factors in the sample. And the notations for the symbols in the sample are included in the Appendix A (see Table A2 in Appendix A). The values of these four factors were set to share the same unit, which is described below.

First, the fare is represented by the symbol $F$. The fare factor represents the fare that the subjects must pay for transportation. In the sample, there are two subjects related to factor $F$, including Pas and Dri. The fare values are set using Formulas (33) and (34):

$$
\begin{gathered}
v\left(\operatorname{Pas}_{t_{m}, s_{p}}(F)\right)=\left\{\begin{array}{c}
-100, t_{m}>t_{1} \text { and } s_{p}=s_{q} \\
0, t_{m} \leq t_{1} \text { or } s_{p} \neq s_{q}
\end{array}\right. \\
v\left(\operatorname{Dri}_{t_{m}, s_{p}}(F)\right)=\left\{\begin{array}{c}
+100, t_{m}>t_{1} \text { and } s_{p}=s_{q} \\
0, t_{m} \leq t_{1} \text { or } s_{p} \neq s_{q}
\end{array}\right.
\end{gathered}
$$

In the sample, the passenger paid money to the taxi driver for the trip when both arrived at the arrival position. It can be seen from Formula (33) that the passenger lost 100 units of value in the fare factor when both arrived at the airport. It can be seen from Formula (34) that the taxi driver gained 100 units value in the fare factor when they arrived at the airport.

Second, business is represented by the symbol $B$. The business factor represents the business that subjects can engage in at a special spacetime. In the sample, there is one subject related to the factor $B$, including Pas. The business value is set using Formula (35):

$$
v\left(\operatorname{Pas}_{t_{m}, s_{p}}(B)\right)=\left\{\begin{array}{l}
+500, t_{1}<t_{m} \leq t_{n} \text { and } s_{p}=s_{q} \\
0, t_{m} \leq t_{1} \text { or } t_{m}>t_{n} \text { or } s_{p} \neq s_{q}
\end{array}\right.
$$

In the sample, the passenger arrived at the arrival position $s_{q}$ at time $t_{n}$ and could then take his plane on time, which is worth 500 units of value. It can be seen from Formula (35) that the passenger could gain 500 units of value in the business factor after arriving at the airport on time. However, he could gain nothing in the business factor if he did not arrive at the airport or arrived at the airport late.

Third, energy is represented by the symbol $E$. The energy factor represents the energy that the subjects exchanged during the transportation process. In the sample, there are three subjects related to the factor E, including Pas, Dri, and Taxi. The energy values are set using Formulas (36)-(38):

$$
\begin{aligned}
& v\left(\operatorname{Pas}_{t_{m}, s_{p}}(E)\right)=\left\{\begin{array}{c}
+\frac{5}{t_{m}-t_{1}}, t_{m}>t_{1} \\
0, t_{m} \leq t_{1}
\end{array}\right. \\
& v\left(\operatorname{Dri}_{t_{m}, s_{p}}(E)\right)=\left\{\begin{array}{c}
-\frac{5}{t_{m}-t_{1}}, t_{m}>t_{1} \\
0, t_{m} \leq t_{1}
\end{array}\right. \\
& v\left(\operatorname{Taxi}_{t_{m}, s_{p}}(E)\right)=\left\{\begin{array}{c}
-\frac{50}{t_{m}-t_{1}}, t_{m}>t_{1} \\
0, t_{m} \leq t_{1}
\end{array}\right.
\end{aligned}
$$

In the sample, the passenger had a rest during the trip, and his energy recovered to some extent, which is worth $\frac{5}{t_{m}-t_{1}}$ units of value per time and 5 units of value in total during the time period $t_{1} \sim t_{m}$ for the energy factor. At the same time, the taxi driver kept driving during the trip, and his energy has declined to some extent, which is worth $\frac{5}{t_{m}-t_{1}}$ unit value per time and 5 units of value in total during 
the time period $t_{1} \sim t_{m}$ in the energy factor. Moreover, taxi energy has declined much to support the transportation process, which is worth $\frac{50}{t_{m}-t_{1}}$ units of value per time and 50 units of value in total during the time period $t_{1} \sim t_{m}$ for the energy factor. It can be seen from Formula (36) that the passenger gained 5 units of value for the energy factor in total during the time period $t_{1} \sim t_{m}$. It can be seen from Formulas (37) and (38) that the taxi driver and the taxi lost a total of 5 units and 50 units of value, respectively, for the energy factor during the time period $t_{1} \sim t_{m}$.

Fourth, pollution is represented by the symbol $P$. The pollution factor represents the pollution that the subjects influence during transportation. In the sample, there are two subjects related to the factor $P$, including Taxi and Tree. The pollution values were set using Formulas (39) and (40):

$$
\begin{gathered}
v\left(\operatorname{Taxi}_{t_{m}, s_{p}}(P)\right)=\left\{\begin{array}{c}
-\frac{8}{t_{m}-t_{1}}, t_{m}>t_{1} \\
0, t_{m} \leq t_{1}
\end{array}\right. \\
v\left(\text { Tree }_{t_{m}, s_{p}}(P)\right)=\left\{\begin{array}{c}
+\frac{6}{t_{m}-t_{1}}, t_{m}>t_{1} \\
0, t_{m} \leq t_{1}
\end{array}\right.
\end{gathered}
$$

In the sample, the taxi output pollution into the air, while the trees conversely contributed to improving the environment. It can be seen from Formula (39) that the taxi created minus $\frac{8}{t_{m}-t_{1}}$ units of value per time and eight units of value in total during the time period $t_{1} \sim t_{m}$ for the pollution factor. It can be seen from Formula (40) that the trees created plus $\frac{6}{t_{m}-t_{1}}$ units of value per time and six units of value in total during the time period $t_{1} \sim t_{m}$ for the pollution factor.

\subsection{Passenger Utility Analyses}

There are four steps in this section.

(i) Calculating individual values. In the sample, the passenger is related to three factors: fare, business, and energy. Based on Formula (24), the individual values of the passenger during the time period $t_{1} \sim t_{m}$ can be calculated by Formula (41):

$$
\left\{\begin{aligned}
v\left(\operatorname{Pas}_{t_{1} \sim t_{m}, s_{1} \sim s_{p}}(F)\right) & =\sum_{i=1}^{m} \sum_{j=1}^{p} v\left(\operatorname{Pas}_{t_{i}, s_{j}}(F)\right) \\
v\left(\operatorname{Pas}_{t_{1} \sim t_{m}, s_{1} \sim s_{p}}(B)\right) & =\sum_{i=1}^{m} \sum_{j=1}^{p} v\left(\operatorname{Pas}_{t_{i}, s_{j}}(B)\right) \\
v\left(\operatorname{Pas}_{t_{1} \sim t_{m}, s_{1} \sim s_{p}}(E)\right) & =\sum_{i=1}^{m} \sum_{j=1}^{p} v\left(\operatorname{Pas}_{t_{i}, s_{j}}(E)\right)
\end{aligned}\right.
$$

Based on Formulas (33) and (41), the individual value of the passenger for the fare factor during the time period $t_{1} \sim t_{m}$ can be calculated by Formula (42):

$$
v\left(\operatorname{Pas}_{t_{1} \sim t_{m}, s_{1} \sim s_{p}}(F)\right)=\left\{\begin{array}{c}
-100, t_{m}>t_{1} \text { and } s_{p}=s_{q} \\
0, t_{m} \leq t_{1} \text { or } s_{p} \neq s_{q}
\end{array}\right.
$$

Based on Formulas (35) and (41), the individual value of the passenger in the business factor during the time period $t_{1} \sim t_{m}$ can be calculated by Formula (43):

$$
v\left(\operatorname{Pas}_{t_{1} \sim t_{m}, s_{1} \sim s_{p}}(B)\right)=\left\{\begin{array}{l}
+500, t_{1}<t_{m} \leq t_{n} \text { and } s_{p}=s_{q} \\
0, t_{m} \leq t_{1} \text { or } t_{m}>t_{n} \text { or } s_{p} \neq s_{q}
\end{array}\right.
$$

Based on Formulas (36) and (41), the individual value of the passenger for the energy factor during the time period $t_{1} \sim t_{m}$ can be calculated by Formula (44):

$$
v\left(\operatorname{Pas}_{t_{1} \sim t_{m}, s_{1} \sim s_{p}}(E)\right)=\left\{\begin{array}{c}
+5, t_{m}>t_{1} \\
0, t_{m} \leq t_{1}
\end{array}\right.
$$


As a result, the individual values of the passenger are calculated for various factors.

(ii) Calculating the total value. The total value of the passenger consists of various individual values for the various passenger factors during the time period $t_{1} \sim t_{m}$ and can be calculated by Formula (45):

$$
V\left(\operatorname{Pas}_{t_{1} \sim t_{m}, s_{1} \sim s_{p}}\right)=v\left(\operatorname{Pas}_{t_{1} \sim t_{m}, s_{1} \sim s_{p}}(F)\right)+v\left(\operatorname{Pas}_{t_{1} \sim t_{m}, s_{1} \sim s_{p}}(B)\right)+v\left(\operatorname{Pas}_{t_{1} \sim t_{m}, s_{1} \sim s_{p}}(E)\right)
$$

Based on Formulas (42)-(44), Formula (45) can be converted into Formula (46):

$$
V\left(\operatorname{Pas}_{t_{1} \sim t_{m}, s_{1} \sim s_{p}}\right)\left\{\begin{array}{c}
0+0+0, t_{m} \leq t_{1} \text { and } s_{p}=s_{q} \\
0+0+0, t_{m} \leq t_{1} \text { and } s_{p} \neq s_{q} \\
-100+500+5, t_{1}<t_{m} \leq t_{n} \text { and } s_{p}=s_{q} \\
0+0+5, t_{1}<t_{m} \leq t_{n} \text { and } s_{p} \neq s_{q} \\
-100+0+5, t_{m}>t_{n} \text { and } s_{p}=s_{q} \\
0+0+5, t_{m}>t_{n} \text { and } s_{p} \neq s_{q}
\end{array}\right.
$$

Formula (46) can then be simplified into Formula (47):

$$
V\left(\text { Pas }_{t_{1} \sim t_{m}, s_{1} \sim s_{p}}\right)=\left\{\begin{array}{c}
+405, t_{1}<t_{m} \leq t_{n} \text { and } s_{p}=s_{q} \\
-95, t_{m}>t_{n} \text { and } s_{p}=s_{q} \\
+5, t_{m}>t_{1} \text { and } s_{p} \neq s_{q} \\
0, t_{m} \leq t_{1}
\end{array}\right.
$$

As a result, the total value of the passenger in the sample can be calculated.

(iii) Calculating the utility. Based on Formula (28), the utility of the passenger can be calculated by Formula (48):

$$
u\left(\operatorname{Pas}_{t_{1} \sim t_{m}, s_{1} \sim s_{p}}(F), \operatorname{Pas}_{t_{1} \sim t_{m}, s_{1} \sim s_{p}}\right)=-\frac{V\left(\operatorname{Pas}_{t_{1} \sim t_{m}, s_{1} \sim s_{p}}\right)}{v\left(\operatorname{Pas}_{t_{1} \sim t_{m}, s_{1} \sim s_{p}}(F)\right)}
$$

Based on Formulas (42) and (46), Formula (48) can be simplified into Formula (49):

$$
u\left(\operatorname{Pas}_{t_{1} \sim t_{m}, s_{1} \sim s_{p}}(F), P a s_{t_{1} \sim t_{m}, s_{1} \sim s_{p}}\right)=\left\{\begin{array}{c}
+4.05, t_{1}<t_{m} \leq t_{n} \text { and } s_{p}=s_{q} \\
-0.95, t_{m}>t_{n} \text { and } s_{p}=s_{q}
\end{array}\right.
$$

As a result, the utility of the passenger in the sample is calculated.

(iv) Analyzing the utility. As shown in Formula (47), there are four situations, and the passenger has different values in different situations. The first situation is $t_{1}<t_{m} \leq t_{n}$ and $s_{p}=s_{q}$, which means that the passenger arrived at the airport on time. Moreover, the total value of the passenger in the first situation is +405 , which means that the passenger benefited greatly from transportation from his home to the airport because he could take his flight. The second situation is $t_{m}>t_{n}$ and $s_{p}=s_{q}$, which means that the passenger arrived at the airport late, and the total value of the passenger in the second situation is -95 , which means that the passenger did not benefit from the transportation from his home to the airport because he was late and missed his flight. The third situation is $t_{m}>t_{1}$ and $s_{p} \neq s_{q}$, which means that the passenger is still on his way to the airport, while the total value of the passenger in the third situation is +5 , which means that he benefited slightly from the transportation because he could relax in the taxi on the way. The fourth situation is $t_{m} \leq t_{1}$, which means that the passenger has not taken a taxi yet, and the total value of the passenger in the fourth situation is 0 as the initial state. It can be seen from Formula (49) that the utility of the passenger in the sample can be divided into two situations. The first situation is $t_{1}<t_{m} \leq t_{n}$ and $s_{p}=s_{q}$, which means that the passenger arrived at the airport on time, and the utility of the passenger is +4.05 . This indicates that transportation from his home to the airport was useful for the passenger and resulted in about a four times total value in return for him. The second situation is $t_{m}>t_{n}$ and $s_{p}=s_{q}$, which means that the 
passenger arrived at the airport late, and the utility of the passenger is -0.95 . This indicates that the transportation from the passenger's home to the airport was not useful for the passenger although he could relax in the taxi on the way.

Thus, the transportation utility of the passenger in the sample is closely related to the passenger's flight, and, in return, his transportation values are also closely related to the value of his flight.

\subsection{Driver Utility Analyses}

There are four steps in this section.

(i) Calculating individual values. In the sample, the taxi driver is related to two factors: fare and energy. Based on Formula (24), the individual values of the passenger during the time period $t_{1} \sim t_{m}$ can be calculated by Formula (50):

$$
\left\{\begin{array}{l}
v\left(\operatorname{Dri}_{t_{1} \sim t_{m}, s_{1} \sim s_{p}}(F)\right)=\sum_{i=1}^{m} \sum_{j=1}^{p} v\left(\operatorname{Dri}_{t_{i}, s_{j}}(F)\right) \\
v\left(D r i_{t_{1} \sim t_{m}, s_{1} \sim s_{p}}(E)\right)=\sum_{i=1}^{m} \sum_{j=1}^{p} v\left(\operatorname{Dri}_{t_{i}, s_{j}}(E)\right)
\end{array}\right.
$$

Based on Formulas (34) and (50), the individual value of the passenger for the fare factor during the time period $t_{1} \sim t_{m}$ can be calculated by Formula (51):

$$
v\left(D r i_{t_{1} \sim t_{m}, s_{1} \sim s_{p}}(F)\right)=\left\{\begin{array}{c}
+100, t_{m}>t_{1} \text { and } s_{p}=s_{q} \\
0, t_{m} \leq t_{1} \text { or } s_{p} \neq s_{q}
\end{array}\right.
$$

Based on Formulas (37) and (50), the individual value of the passenger for the energy factor during the time period $t_{1} \sim t_{m}$ can be calculated by Formula (52):

$$
v\left(D r i_{t_{1} \sim t_{m}, s_{1} \sim s_{p}}(E)\right)=\left\{\begin{array}{c}
-5, t_{m}>t_{1} \\
0, t_{m} \leq t_{1}
\end{array}\right.
$$

As a result, the individual values of the taxi driver are calculated for various factors.

(ii) Calculating the total value. The total value of the taxi driver consists of all his individual values for various factors during the time period $t_{1} \sim t_{m}$, which can be calculated by Formula (53):

$$
V\left(D r i_{t_{1} \sim t_{m}, s_{1} \sim s_{p}}\right)=v\left(D r i_{t_{1} \sim t_{m}, s_{1} \sim s_{p}}(F)\right)+v\left(D r i_{t_{1} \sim t_{m}, s_{1} \sim s_{p}}(E)\right)
$$

Based on Formulas (51) and (52), Formula (53) can be converted into Formula (54):

$$
V\left(D r i_{t_{1} \sim t_{m}, s_{1} \sim s_{p}}\right)=\left\{\begin{array}{c}
+100-5, t_{m}>t_{1} \text { and } s_{p}=s_{q} \\
0-5, t_{m}>t_{1} \text { and } s_{p} \neq s_{q} \\
0+0, t_{m} \leq t_{1}
\end{array}\right.
$$

Formula (54) can then be simplified into Formula (55):

$$
V\left(D r i_{t_{1} \sim t_{m}, s_{1} \sim s_{p}}\right)=\left\{\begin{array}{c}
+95, t_{m}>t_{1} \text { and } s_{p}=s_{q} \\
-5, t_{m}>t_{1} \text { and } s_{p} \neq s_{q} \\
0, t_{m} \leq t_{1}
\end{array}\right.
$$

As a result, the total value of the taxi driver in the sample is calculated.

(iii) Calculating the utility. Based on Formula (28), the utility of the taxi driver can be calculated by Formula (56):

$$
u\left(\operatorname{Dri}_{t_{1} \sim t_{m}, s_{1} \sim s_{p}}(E), \operatorname{Dri}_{t_{1} \sim t_{m}, s_{1} \sim s_{p}}\right)=-\frac{V\left(\operatorname{Pas}_{t_{1} \sim t_{m}, s_{1} \sim s_{p}}\right)}{v\left(\operatorname{Pas}_{t_{1} \sim t_{m}, s_{1} \sim s_{p}}(E)\right)}
$$


Based on Formulas (52) and (55), Formula (56) can be simplified into Formula (57):

$$
u\left(D r i_{t_{1} \sim t_{m}, s_{1} \sim s_{p}}(E), D r i_{t_{1} \sim t_{m}, s_{1} \sim s_{p}}\right)=\left\{\begin{array}{c}
+19, t_{m}>t_{1} \text { and } s_{p}=s_{q} \\
-1, t_{m}>t_{1} \text { and } s_{p} \neq s_{q}
\end{array}\right.
$$

As a result, the utility of the taxi driver in the sample is calculated.

(iv) Analyzing the utility. It can be seen from Formula (55) that there are three situations, and the taxi driver has different values in different situations. The first situation is $t_{m}>t_{1}$ and $s_{p}=s_{q}$, which means that the driver and passenger arrived at the airport, and the total value of the taxi driver in the first situation is +95 , which means that the taxi driver benefited greatly from the transportation because he could obtain a fare from the passenger. The second situation is $t_{m}>t_{1}$ and $s_{p} \neq s_{q}$, which means that the taxi is still on its way to the airport, and the total value of the taxi driver in the second situation is -5 , which means the driver lost energy from engaging in the transportation because he drove the taxi, which made him tired. The third situation is $t_{m} \leq t_{1}$, which means that the taxi driver has not picked up the passenger yet, and the total value of the taxi driver in the third situation is 0 as the initial state. It can be seen from Formula (57) that the utility of the taxi driver in the sample can be divided into two situations. The first situation is $t_{m}>t_{1}$ and $s_{p}=s_{q}$, which means that the passenger and driver arrived at the airport, and the utility of the taxi driver in the first situation is +19. This indicates that transportation was quite useful for the taxi driver and yielded about 19 times the total value in return for him. The second situation is $t_{m}>t_{1}$ and $s_{p} \neq s_{q}$, which means that both parties had not arrived at the airport yet, and the utility of the taxi driver in the second situation is -1 . This indicates that the taxi driver lost value but received no value in return yet.

Thus, the transportation utility of the taxi driver in the sample is closely related to whether the trip is finished nor not, and, in return, his transportation values are also closely related to the value of the taxi fare.

\subsection{Additional Analyses}

In Sections 4.2 and 4.3, two values of the taxi are ignored. In the sample, the taxi is related to two factors, energy and pollution, and the values of the taxis for these 2 factors have effects on the other participants, which are analyzed as follows.

(i) Taxi energy analysis. The energy that the taxi uses is the cost of the taxi driver. Based on Formula (24), the individual values of the passenger during the time period $t_{1} \sim t_{m}$ can be calculated by Formula (58):

$$
v\left(\operatorname{Taxi}_{t_{1} \sim t_{m}, S_{1} \sim s_{p}}(E)\right)=\sum_{i=1}^{m} \sum_{j=1}^{p} v\left(\operatorname{Taxi}_{t_{i}, s_{j}}(E)\right)
$$

Based on Formulas (38) and (58), the individual value of the taxi for the energy factor during the time period $t_{1} \sim t_{m}$ can be calculated by Formula (59):

$$
v\left(\operatorname{Taxi}_{t_{1} \sim t_{m}, s_{1} \sim s_{p}}(E)\right)=\left\{\begin{array}{c}
-50, t_{m}>t_{1} \\
0, t_{m} \leq t_{1}
\end{array}\right.
$$

Taking taxi energy into consideration, the total value of the taxi driver consists of various driver's individual values for various factors and the individual value of the taxi for the energy factor during the time period $t_{1} \sim t_{m}$, which can be calculated by Formula (60):

$$
V\left(D r i_{t_{1} \sim t_{m}, s_{1} \sim s_{p}}\right)=v\left(D r i_{t_{1} \sim t_{m}, s_{1} \sim s_{p}}(F)\right)+v\left(D r i_{t_{1} \sim t_{m}, s_{1} \sim s_{p}}(E)\right)+v\left(\operatorname{Taxi}_{t_{1} \sim t_{m}, s_{1} \sim s_{p}}(E)\right)
$$


Based on Formulas (51), (52) and (59), Formula (60) can be converted into Formula (61):

$$
V\left(\text { Dri }_{t_{1} \sim t_{m}, s_{1} \sim s_{p}}\right)=\left\{\begin{array}{c}
+100-5-50, t_{m}>t_{1} \text { and } s_{p}=s_{q} \\
0-5-50, t_{m}>t_{1} \text { and } s_{p} \neq s_{q} \\
0+0, t_{m} \leq t_{1}
\end{array}\right.
$$

Formula (61) can be simplified into Formula (62):

$$
V\left(D r i_{t_{1} \sim t_{m}, s_{1} \sim s_{p}}\right)=\left\{\begin{array}{c}
+45, t_{m}>t_{1} \text { and } s_{p}=s_{q} \\
-55, t_{m}>t_{1} \text { and } s_{p} \neq s_{q} \\
0, t_{m} \leq t_{1}
\end{array}\right.
$$

Based on Formulas (52) and (62), the utility of the taxi driver can be calculated by Formula (63):

$$
u\left(D r i_{t_{1} \sim t_{m}, s_{1} \sim s_{p}}(E), D r i_{t_{1} \sim t_{m}, s_{1} \sim s_{p}}\right)=\left\{\begin{array}{c}
+9, t_{m}>t_{1} \text { and } s_{p}=s_{q} \\
-11, t_{m}>t_{1} \text { and } s_{p} \neq s_{q}
\end{array}\right.
$$

It can be seen from Formula (63) that the utility of the taxi driver in the sample can be divided into two situations. The first situation is $t_{m}>t_{1}$ and $s_{p}=s_{q}$, and the utility of the taxi driver is +9 . The second situation is $t_{m}>t_{1}$ and $s_{p} \neq s_{q}$, and the utility of the taxi driver is - 11 . Comparing the results of Formulas (57) and (63), it can be seen that the utility of the taxi driver in the first situation is reduced from +19 to +9 , and the utility of the taxi driver in the second situation is reduced from -1 to -11 . This indicates that it was necessary to take the values of the taxi into consideration when analyzing the utility of the taxi driver.

(ii) Taxi pollution analysis. The pollution that the taxi produced was harmful to the environment. Based on Formula (24), the pollution values of the taxi and trees during the time period $t_{1} \sim t_{m}$ can be calculated by Formula (64):

$$
\left\{\begin{array}{l}
v\left(\operatorname{Taxi}_{t_{1} \sim t_{m}, s_{1} \sim s_{p}}(P)\right)=\sum_{i=1}^{m} \sum_{j=1}^{p} v\left(\operatorname{Taxi}_{t_{i}, s_{j}}(P)\right) \\
v\left(\operatorname{Tree}_{t_{1} \sim t_{m}, s_{1} \sim s_{p}}(P)\right)=\sum_{i=1}^{m} \sum_{j=1}^{p} v\left(\operatorname{Tree}_{t_{i}, s_{j}}(P)\right)
\end{array}\right.
$$

Based on Formulas (39) and (64), the individual value of the taxi for the pollution factor during the time period $t_{1} \sim t_{m}$ can be calculated by Formula (65):

$$
v\left(\operatorname{Taxi}_{t_{1} \sim t_{m}, s_{1} \sim s_{p}}(P)\right)=-8
$$

Based on Formulas (40) and (64), the individual value of trees for the pollution factor during the time period $t_{1} \sim t_{m}$ can be calculated by Formula (66):

$$
v\left(\text { Tree }_{t_{1} \sim t_{m}, s_{1} \sim s_{p}}(P)\right)=+6
$$

Based on Formulas (65) and (66), the summation of the individual values of the taxi and trees for the pollution factor during the time period $t_{1} \sim t_{m}$ can be calculated by Formula (67):

$$
v\left(\operatorname{Taxi}_{t_{1} \sim t_{m}, s_{1} \sim s_{p}}(P)\right)+v\left(\operatorname{Tree}_{t_{1} \sim t_{m}, s_{1} \sim s_{p}}(P)\right)=-8+6=-2<0
$$

It can be seen from Formula (67) that the summation is a negative number. This indicates that the environment cannot recover at this moment because the taxi pollution is higher than the purification function of the trees.

Suppose that the taxi uses clean energy instead of fossil energies, and its pollution is reduced by half. At present, the taxi creates minus $\frac{4}{t_{m}-t_{1}}$ units of value per time and four units of value in total 
during the time period $t_{1} \sim t_{m}$ for the pollution factor. The new individual value of the taxi for the pollution factor during the time period $t_{1} \sim t_{m}$ can then be calculated by Formula (68):

$$
v^{\prime}\left(\operatorname{Taxi}_{t_{1} \sim t_{m}, s_{1} \sim s_{p}}(P)\right)=-4
$$

Based on Formulas (66) and (68), the new summation of the individual values of the taxi and trees for the pollution factor during the time period $t_{1} \sim t_{m}$ can be calculated by Formula (69):

$$
v^{\prime}\left(\operatorname{Taxi}_{t_{1} \sim t_{m}, s_{1} \sim s_{p}}(P)\right)+v\left(\text { Tree }_{t_{1} \sim t_{m}, s_{1} \sim \mathcal{S}_{p}}(P)\right)=-4+6=+2>0
$$

It can be seen from Formula (69) that the summation is a negative number. This indicates that the environment can recover at this moment because the taxi's pollution is lower than the purification function of the trees.

Comparing the two above situations, it can be seen that the pollution output from the taxi to the environment should not be ignored. Furthermore, taxis that use clean energy instead of fossil energies would be friendlier to the environment.

Compared with traditional utility theory, the Transportation Utility Method considers PT problems from multiple perspectives. The energy used by the taxi and the pollution output by the taxi were easily ignored in related studies. Thus, the values and utility calculated by the Transportation Utility Method are more objective and accurate.

\section{Application}

\subsection{Background}

The original data were collected by a GPS-equipped taxi in Haikou City, which is located in Hainan Island. A map of Hainan Island was drawn by Amap, a map service provider of China (see Figure 9). In Figure 9, there is a red dotted-line circle. It indicates that Haikou City is located in the north of Hainan Island.

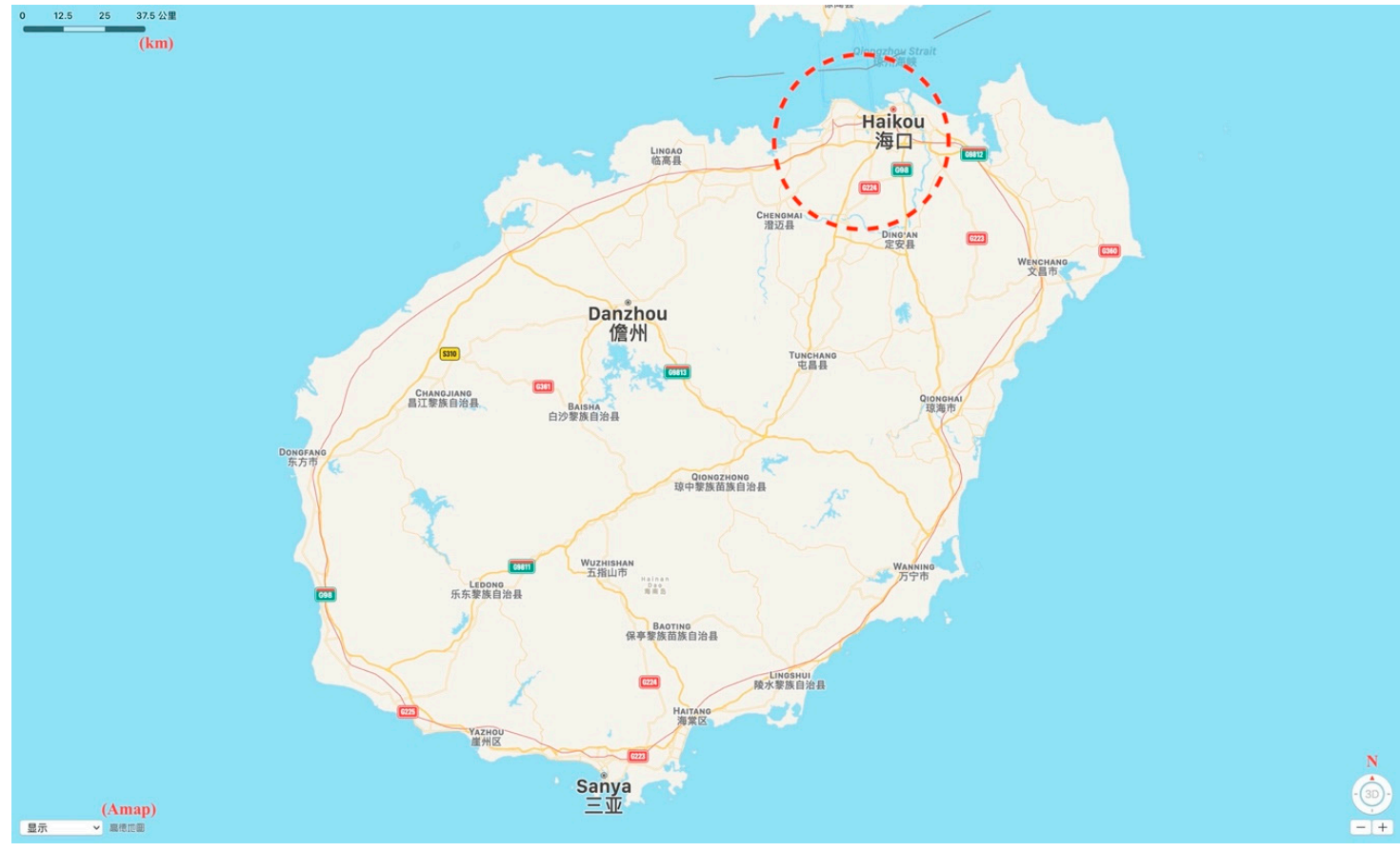

Figure 9. A real map of Hainan Island, drawn by Amap. 
A location map of Hainan Island with Haikou City inside was drawn by Stata (see Figure 10). In Figure 10, the red border represents the area of Hainan Island, while the green border represents the area of Haikou City.

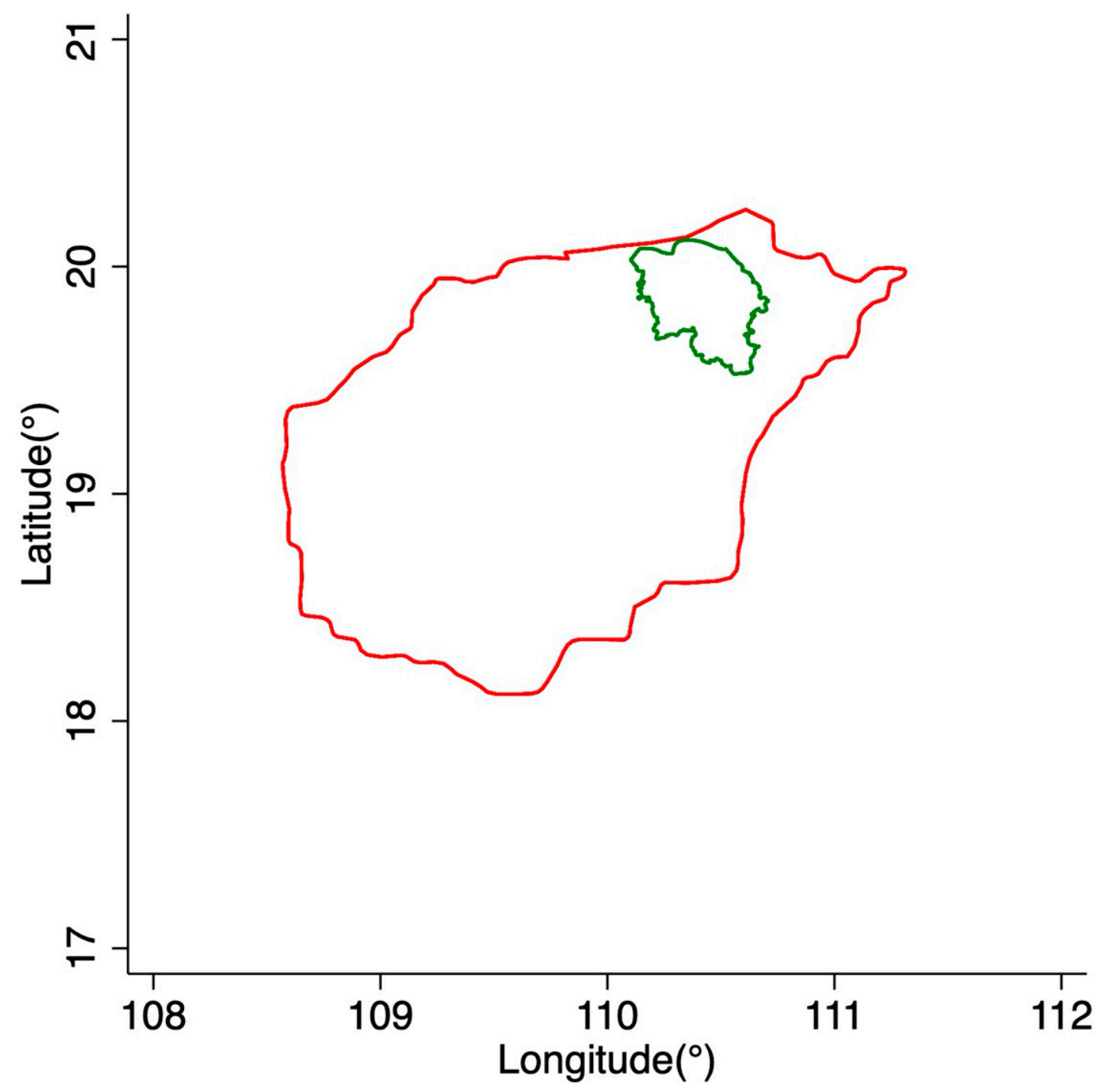

Figure 10. A location map of Hainan Island with Haikou City inside, drawn by Stata.

Hainan Province is a province in southern China. Hainan Island is the biggest island in Hainan Province, where the longitude is in the range $108.569^{\circ}-111.312^{\circ}$, and the latitude is in the range of $18.117^{\circ}-20.251^{\circ}$. Moreover, the altitude in Hainan Island is in the range $-108-1794 \mathrm{~m}$. An elevation map of Hainan Island was drawn by Global Mapper (see Figure 11). In Figure 11, colours reflect the elevation. Blue areas represent low altitudes, green areas represent medium altitudes, and yellow and red areas represent high altitudes. 

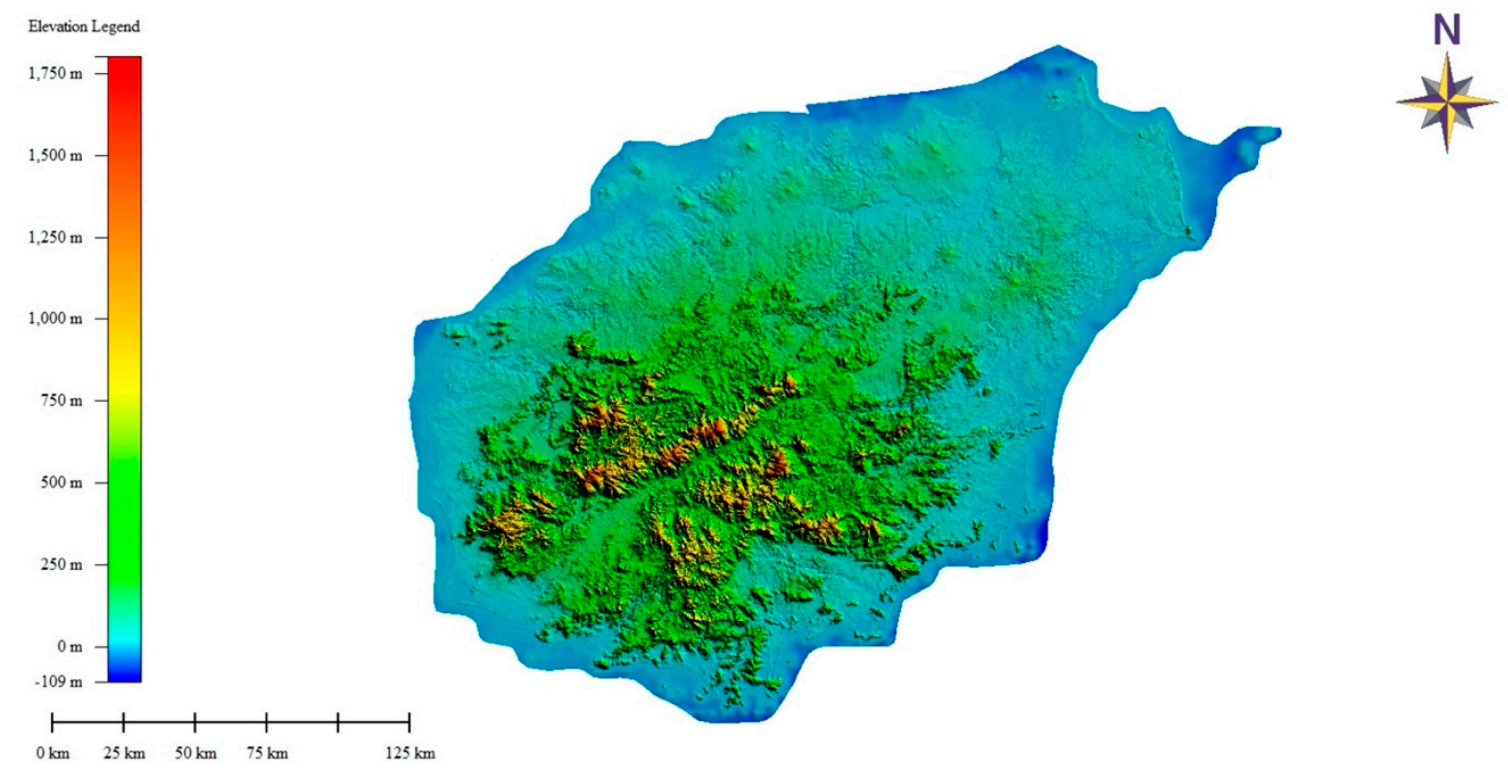

Figure 11. An elevation map of Hainan Island, drawn by Global Mapper.

Haikou City is the capital city of Hainan Province where the longitude is in the range $110.102^{\circ}-110.710^{\circ}$, and the latitude is in the range of $19.525^{\circ}-20.118^{\circ}$. Moreover, the altitude in Haikou City is in the range -17-188 m. An elevation map of Haikou City was drawn by Global Mapper (see Figure 12). In Figure 12, colours reflect the elevation. Blue areas represent low altitudes, green areas represent medium altitudes, and yellow and red areas represent high altitudes.
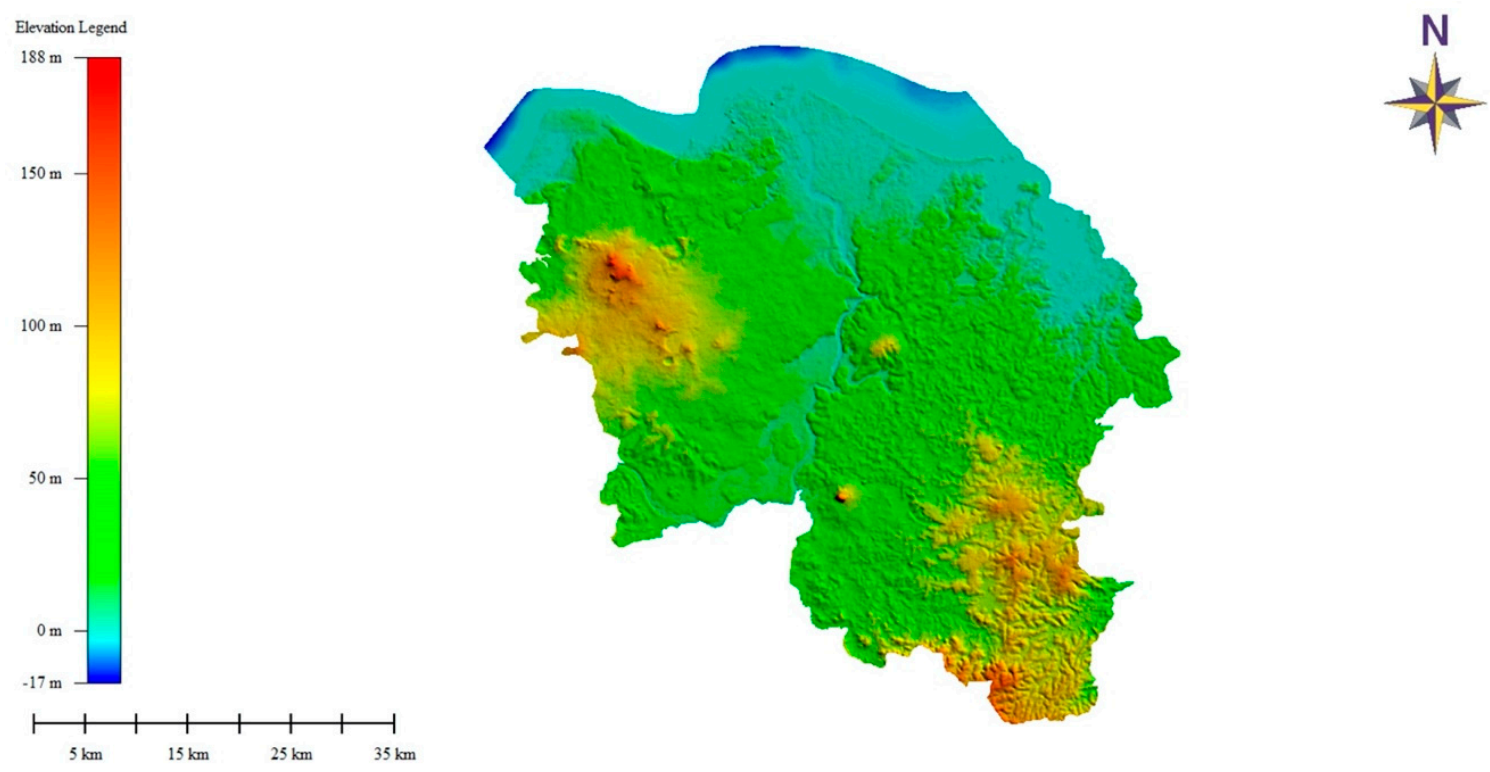

Figure 12. An elevation map of Haikou City, drawn by Global Mapper.

It can be seen that significant altitude differences exist in different areas of Hainan Island and Haikou City. Thus, Formula (32) was adopted to analyze vehicle movements to improve the precision of GPS data with altitude.

Five hospitals and one airport were selected for analyses (see Table 1). In Table 1, No. a-e represent five local hospitals in Haikou City. These five hospitals are famous in local and they all meet the requirements of third-class hospitals, which means that these hospitals have the highest standards in China. f represents the only one airport in Haikou City, Haikou Meilan International Airport. It is addressed by Meilan International Airport for short in this paper. 
Table 1. Specific names of 5 hospitals and 1 airport in Haikou City.

\begin{tabular}{ccc}
\hline No & Type & Name \\
\hline a & Hospital & Hainan General Hospital \\
b & Hospital & The Second Affiliated Hospital of Hainan Medical University \\
c & Hospital & The First Affiliated Hospital of Hainan Medical University \\
d & Hospital & Haikou People's Hospital \\
e & Hospital & Hainan Hospital of Traditional Chinese Medicine \\
f & Airport & Haikou Meilan International Airport \\
\hline
\end{tabular}

A real map of partial Haikou City was drawn by Amap, a map service provider of China (see Figure 13). In Figure 13, there are five red circles made of dotted lines on the left. They indicate that five hospitals are located in the northwest of Haikou City. There is one red square frame made from a dotted line on the right. It indicates that Meilan International Airport is located in the southeast of Haikou City.

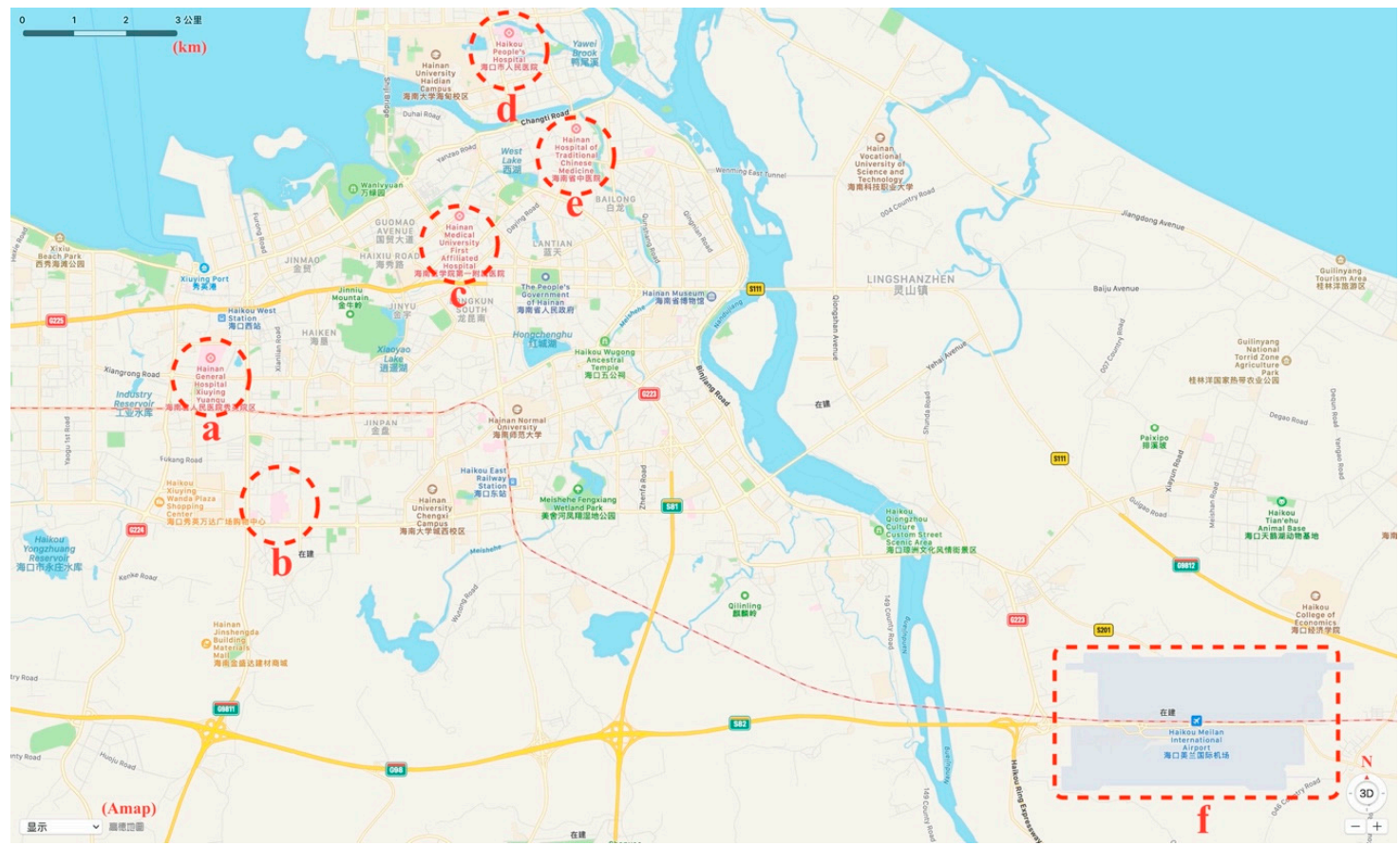

Figure 13. A real map of partial Haikou City, drawn by Amap.

During data cleansing, it was found that Hainan General Hospital was most popular on 1 May 2017 according to the original data because its quantity of arrived taxis was higher than that of the other hospitals. Thus, Hainan General Hospital was chosen as the only hospital to analyze.

As a result, Meilan International Airport and Hainan General Hospital were chosen as the objects to analyze. A location map of Haikou City with Meilan International Airport and Hainan General Hospital inside was drawn by Stata (see Figure 14). In Figure 14, the red border represents the area of Haikou City, with two green areas. The big green area on the right represents the area of Meilan International Airport, while the small one on the left represents the area of Hainan General Hospital. 


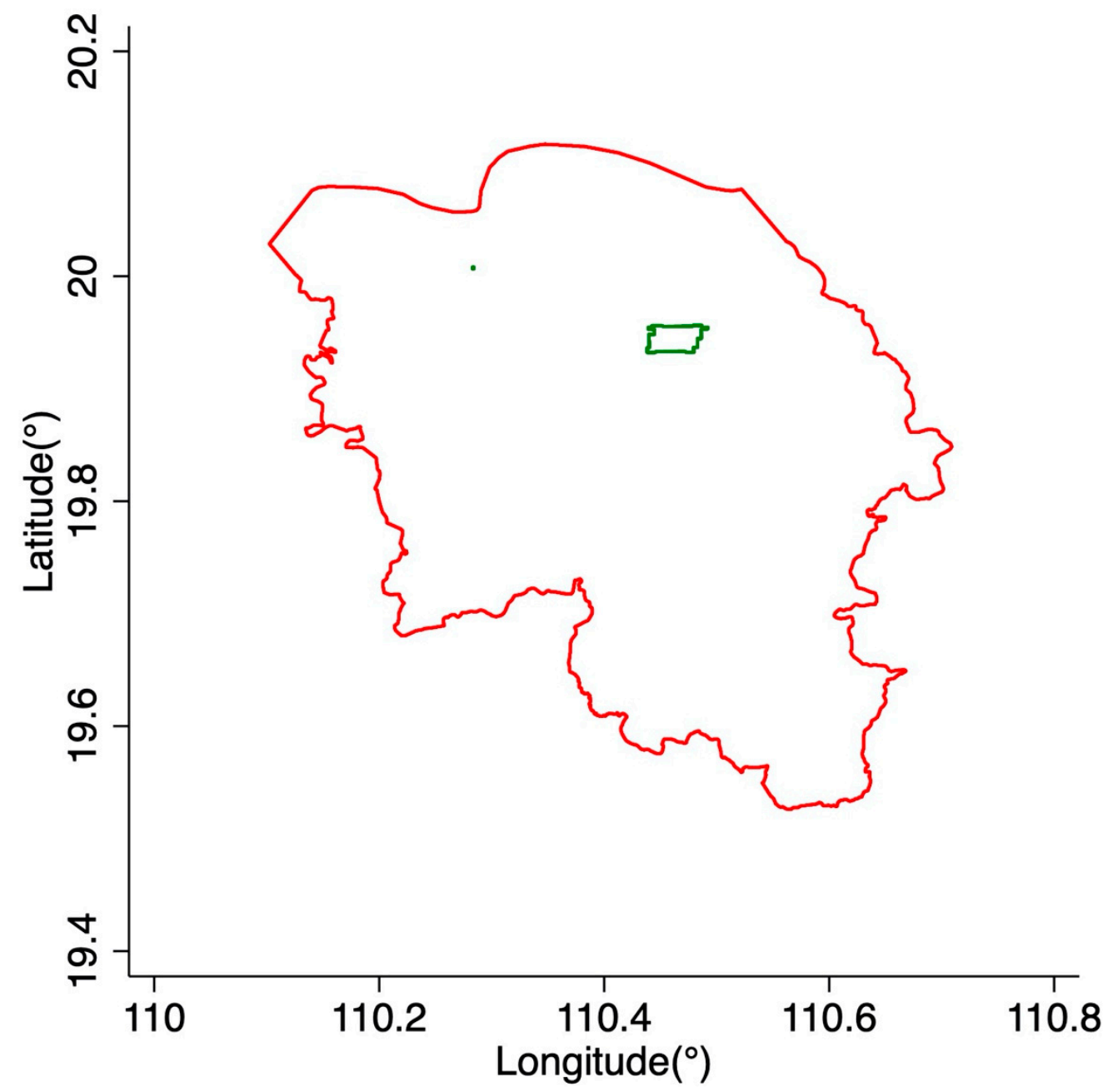

Figure 14. A location map of Haikou City with Meilan International Airport and Hainan General Hospital inside, drawn by Stata.

\subsection{Passenger Utility Analyses}

The reasons that passengers take taxis depend on their trip purposes. In this paper, there are two special purposes given high values. One is catching a plane, and the other is emergency treatment. In this section, an airport and a hospital are focused upon to analyze passenger utility.

To begin with, two hypotheses are given below:

1. For all the passengers who arrived at an airport by taxi, their trip purpose is to catch a plane.

2. For all the passengers who arrived in a hospital by taxi, their trip purpose is to ask for emergency treatment.

There are two parts in this section.

(i) Meilan International Airport. Meilan International Airport is the main airport in Haikou, with longitude in the range $110.438^{\circ}-110.493^{\circ}$ and latitude in the range $19.932^{\circ}-19.957^{\circ}$. According to the processed data, there are 197 records on taxis that arrived in the area of Meilan International Airport on 1 May 2017 (see Table 2). In Table 2, the Record ID represents the number of records listed in the original data. Among these 197 records, the departure time is in the range 0:08-23:14, while the arrival time is in the range 0:10-23:16. 
Table 2. Specific information of 197 Taxis which arrived in Meilan International Airport.

\begin{tabular}{cccccccc}
\hline No & $\begin{array}{c}\text { Departure } \\
\text { Time }\end{array}$ & $\begin{array}{c}\text { Departure } \\
\text { Longitude }\end{array}$ & $\begin{array}{c}\text { Departure } \\
\text { Latitude }\end{array}$ & $\begin{array}{c}\text { Arrival } \\
\text { Time }\end{array}$ & $\begin{array}{c}\text { Arrival } \\
\text { Longitude }\end{array}$ & $\begin{array}{c}\text { Arrival } \\
\text { Latitude }\end{array}$ & Record ID \\
\hline 1 & $0: 08$ & 110.4350 & 19.9677 & $0: 10$ & 110.4515 & 19.9404 & 35424 \\
2 & $0: 51$ & 110.4367 & 19.9674 & $0: 53$ & 110.4501 & 19.9400 & 36052 \\
3 & $1: 56$ & 110.4380 & 19.9662 & $2: 01$ & 110.4501 & 19.9418 & 56309 \\
4 & $3: 20$ & 110.3414 & 20.0278 & $3: 32$ & 110.4634 & 19.9369 & 55054 \\
5 & $4: 13$ & 110.4362 & 19.9646 & $4: 22$ & 110.4634 & 19.9369 & 33077 \\
$\ldots$ & $\ldots$ & $\ldots$ & $\ldots$ & $\ldots$ & $\ldots$ & $\ldots$ & $\ldots$ \\
193 & $21: 54$ & 110.4991 & 19.9389 & $21: 57$ & 110.4634 & 19.9369 & 59140 \\
194 & $22: 33$ & 110.4967 & 19.9407 & $22: 36$ & 110.4634 & 19.9369 & 60617 \\
195 & $22: 39$ & 110.4354 & 19.9675 & $22: 41$ & 110.4502 & 19.9421 & 3715 \\
196 & $22: 38$ & 110.3593 & 20.0039 & $22: 53$ & 110.4634 & 19.9369 & 54695 \\
197 & $23: 14$ & 110.4392 & 19.9645 & $23: 16$ & 110.4671 & 19.9446 & 42153 \\
\hline
\end{tabular}

The durations are within the range 2-28 $\mathrm{min}$ (see Figure 15). In Figure 15, the unit of duration is minutes. The longest trip (Record ID: 18986) was $28 \mathrm{~min}$.

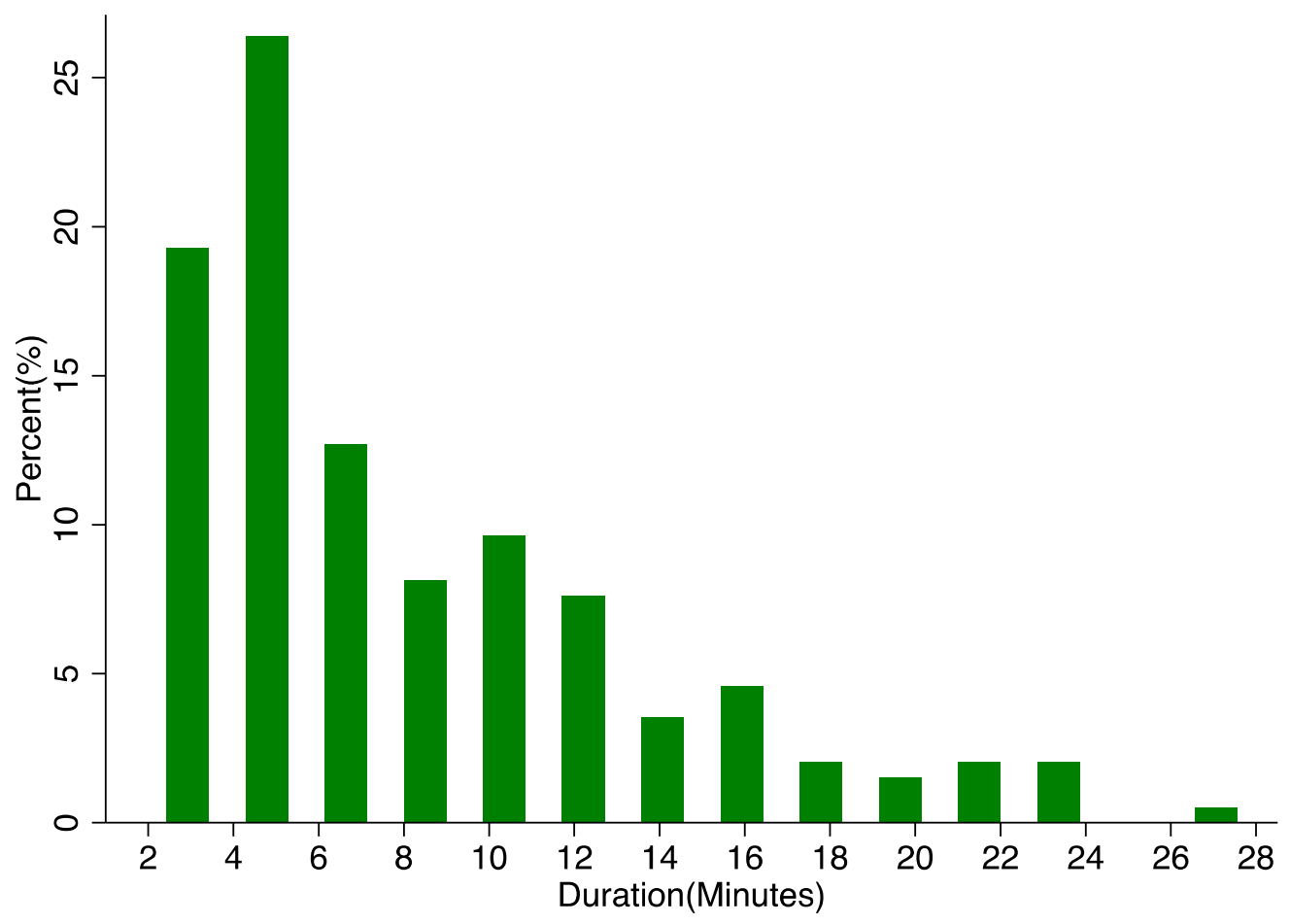

Figure 15. A per cent histogram of taxi durations in 197 records that arrived at Meilan International Airport, drawn by Stata.

The longitudes of the departure positions are in the range $110.222^{\circ}-110.518^{\circ}$, while the latitudes of the arrival positions are in the range $19.919^{\circ}-20.068^{\circ}$ (see Figure 16). In Figure 16, the red border represents the area of Meilan International Airport, while blue triangles represent the departure positions. 


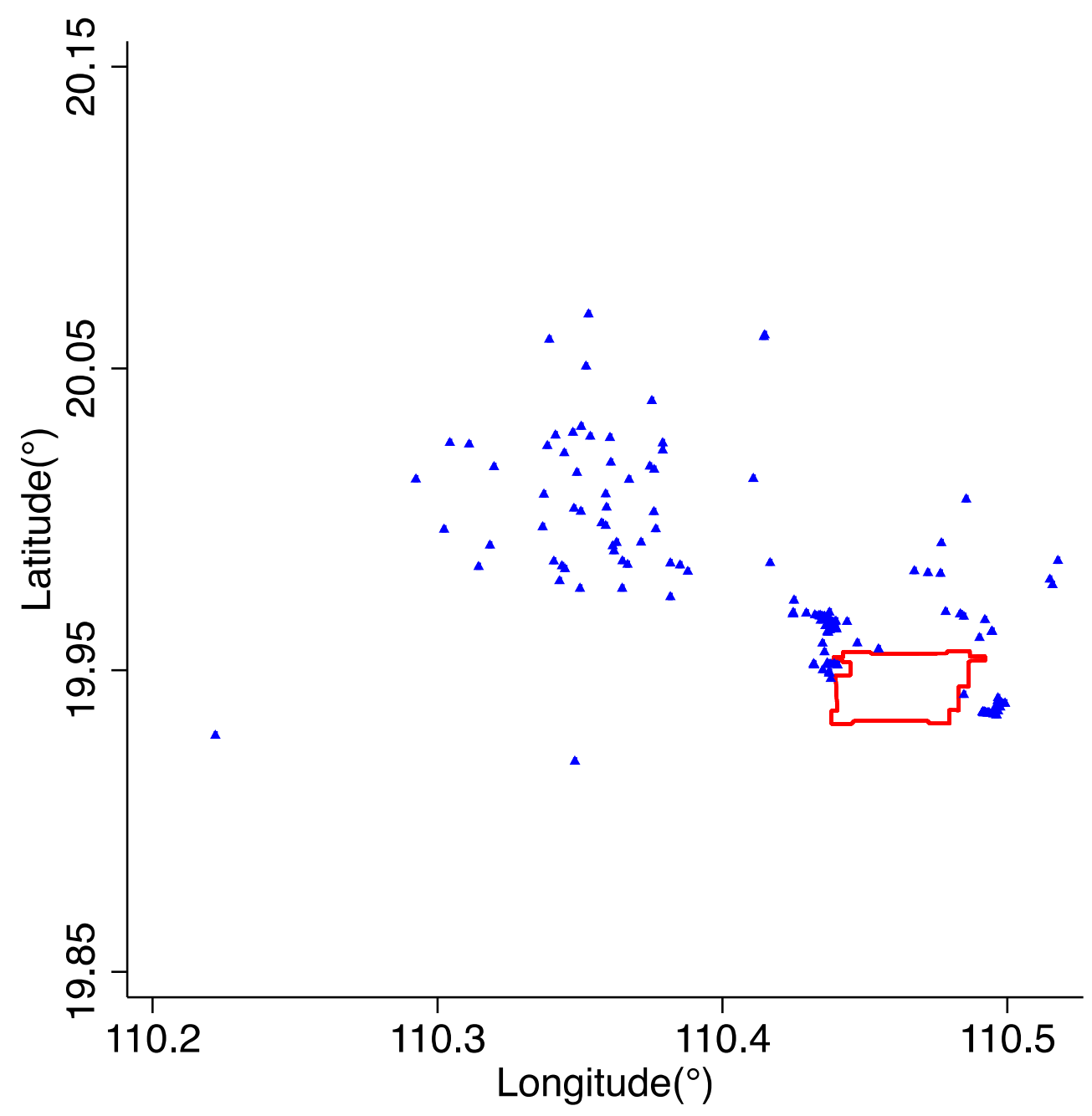

Figure 16. A location map of departure positions of 197 taxis arrived at Meilan International Airport, drawn by Stata.

The longitudes of the departure positions are in the range $110.450^{\circ}-110.482^{\circ}$, while the latitudes of the arrival positions are in the range of $19.936^{\circ}-19.945^{\circ}$ (see Figure 17). In Figure 17, the red border represents the area of Meilan International Airport, while the blue triangles represent the departure positions.

It can be seen that most trips to Meilan International Airport were shorter than $20 \mathrm{~min}$. Furthermore, many departure positions were close to the area of Meilan International Airport. This indicates that the passengers paid great attention to their flights. Indeed, some passengers even lived in hotels around the airport the day before their flights to ensure that they would arrive at the airport in advance. For the passengers intending to take flights, it is important to arrive at the airport in advance. If passengers do not arrive at the airport on time, they will miss their flights.

Thus, the passengers' transportation utility is closely related to their flights. Moreover, their transportation values are also closely related to the values of their flights. 


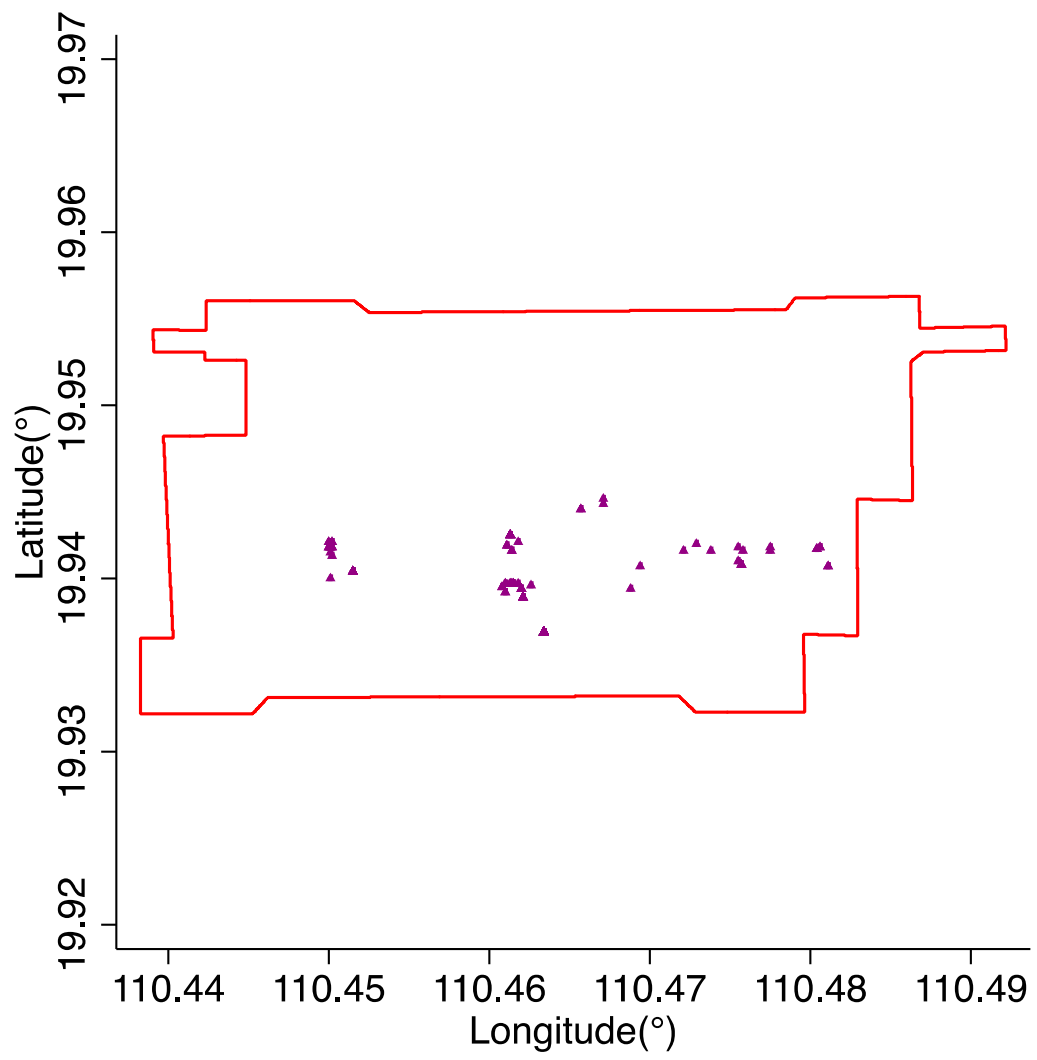

Figure 17. A location map of arrival positions of 197 taxis arrived at Meilan International Airport, drawn by Stata.

(ii) Hainan General Hospital. Hainan General Hospital is one of the largest hospitals in Haikou, where the longitude is in the range $110.282^{\circ}-110.285^{\circ}$, and the latitude is in the range of $20.006^{\circ}-20.009^{\circ}$. According to the processed data, there were 40 records for taxis that arrived in the area of Hainan General Hospital on 1 May 2017 (see Table 3). In Table 3, the Record ID represents the number of records listed in the original data. In these 197 records, the departure time is in the range 1:47-22:59, while the arrival time is in the range 1:55-23:04.

Table 3. Specific information of 40 Taxis which arrived in Hainan General Hospital.

\begin{tabular}{cccccccc}
\hline No & $\begin{array}{c}\text { Departure } \\
\text { Time }\end{array}$ & $\begin{array}{c}\text { Departure } \\
\text { Longitude }\end{array}$ & $\begin{array}{c}\text { Departure } \\
\text { Latitude }\end{array}$ & $\begin{array}{c}\text { Arrival } \\
\text { Time }\end{array}$ & $\begin{array}{c}\text { Arrival } \\
\text { Longitude }\end{array}$ & $\begin{array}{c}\text { Arrival } \\
\text { Latitude }\end{array}$ & Record ID \\
\hline 1 & $1: 47$ & 110.3359 & 20.0358 & $1: 55$ & 110.2842 & 20.0072 & 10695 \\
2 & $2: 44$ & 110.3028 & 20.0218 & $2: 50$ & 110.2842 & 20.0071 & 41373 \\
3 & $8: 11$ & 110.3346 & 20.0268 & $8: 16$ & 110.2842 & 20.0071 & 11372 \\
4 & $8: 34$ & 110.2825 & 20.0198 & $8: 39$ & 110.2837 & 20.0075 & 50602 \\
5 & $9: 15$ & 110.2711 & 20.0189 & $9: 17$ & 110.2842 & 20.0071 & 2267 \\
$\ldots$ & $\ldots$ & $\ldots$ & $\ldots$ & $\ldots$ & $\ldots$ & $\ldots$ & $\ldots$ \\
36 & $21: 28$ & 110.3177 & 20.0316 & $21: 35$ & 110.2842 & 20.0071 & 54147 \\
37 & $21: 37$ & 110.262 & 20.0116 & $21: 45$ & 110.2842 & 20.0071 & 44181 \\
38 & $21: 46$ & 110.3487 & 20.0159 & $21: 51$ & 110.2842 & 20.0073 & 42832 \\
39 & $21: 46$ & 110.3201 & 20.0279 & $21: 53$ & 110.2842 & 20.0071 & 23675 \\
40 & $22: 59$ & 110.3424 & 20.0479 & $23: 04$ & 110.2842 & 20.0071 & 13353 \\
\hline
\end{tabular}

The longitudes of the departure positions were in the range $110.237^{\circ}-110.364^{\circ}$, while the latitudes of the departure positions were in the range $19.976^{\circ}-20.048^{\circ}$ (see Figure 18). In Figure 18, the red border represents the area of Hainan General Hospital, while the blue triangles represent the departure positions. 


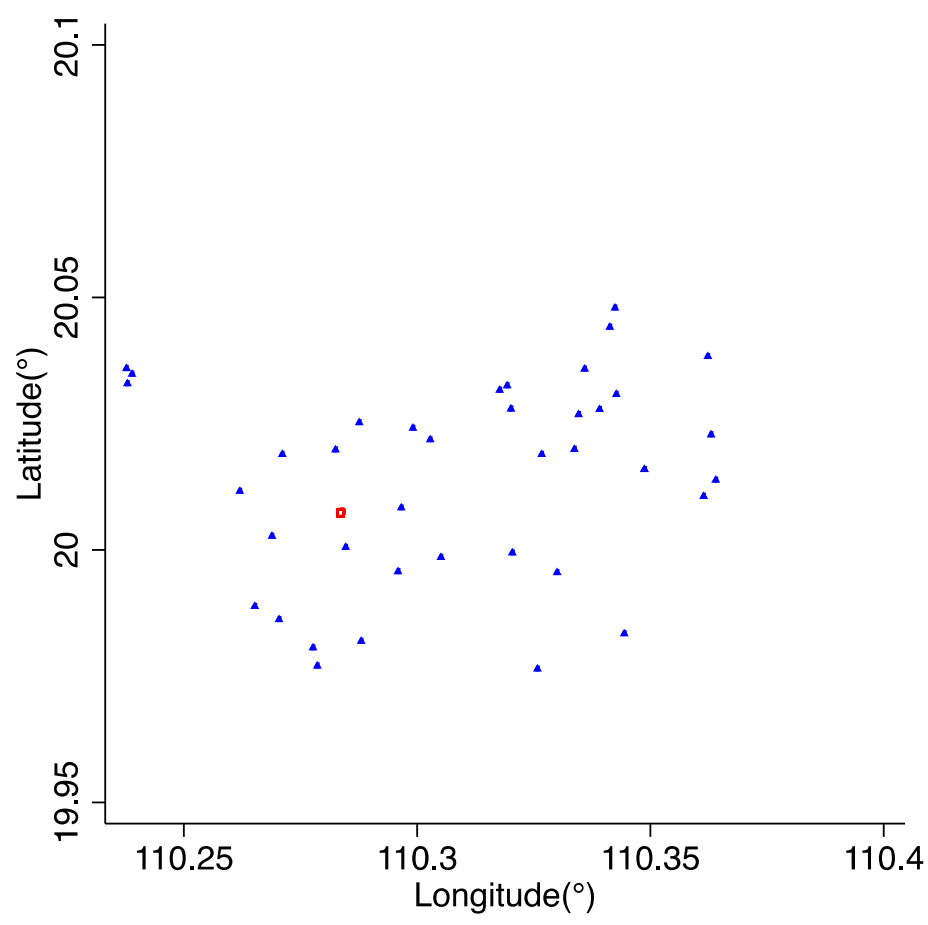

Figure 18. A location map of departure positions of 40 taxis arrived at Hainan General Hospital, drawn by Stata.

The longitudes of the arrival positions were in the range $110.283^{\circ}-110.285^{\circ}$, while the latitudes of the arrival positions were in the range $20.007^{\circ}-20.008^{\circ}$ (see Figure 19). In Figure 19, the red border represents the area of Hainan General Hospital, while the purple triangles represent the arrival positions.

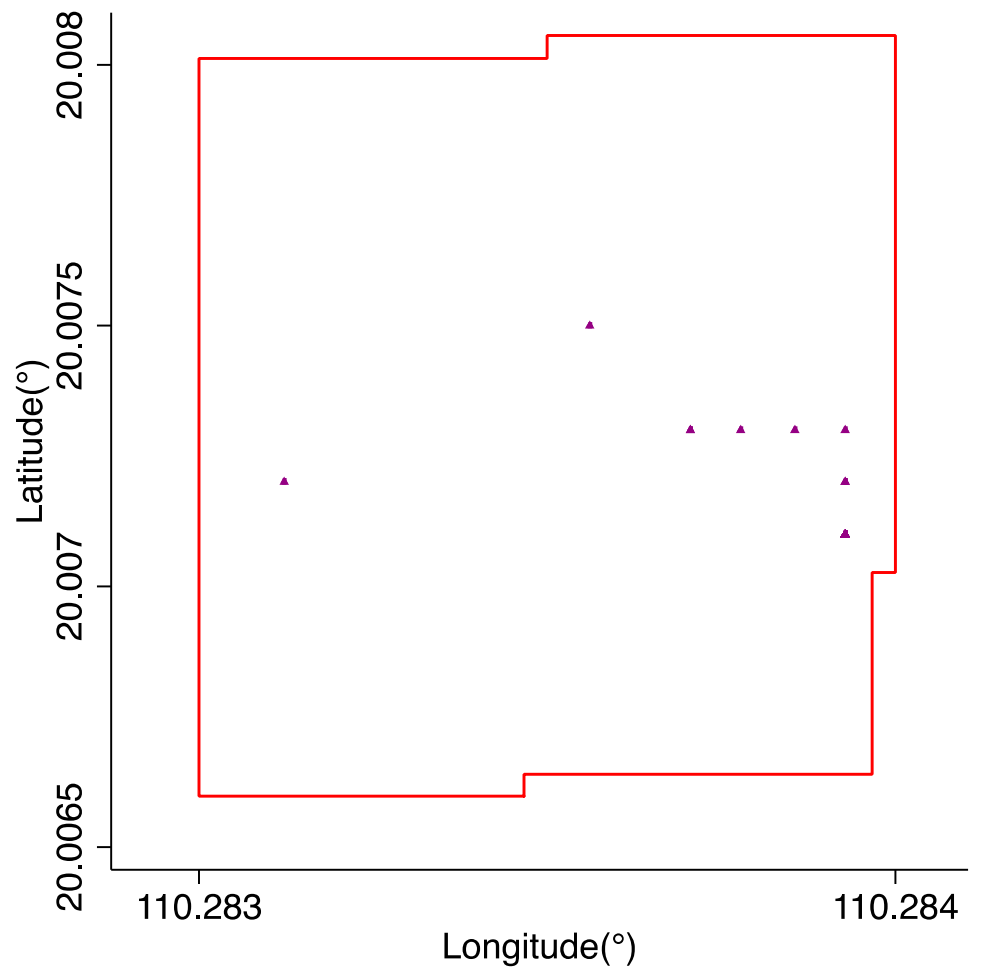

Figure 19. A location map of arrival positions of 40 taxis arrived at Hainan General Hospital, drawn by Stata. 
The durations were in the range 3-10 min (see Figure 20). In Figure 20, the unit of duration is minutes. The longest trip (Record ID: 56918) was $10 \mathrm{~min}$.

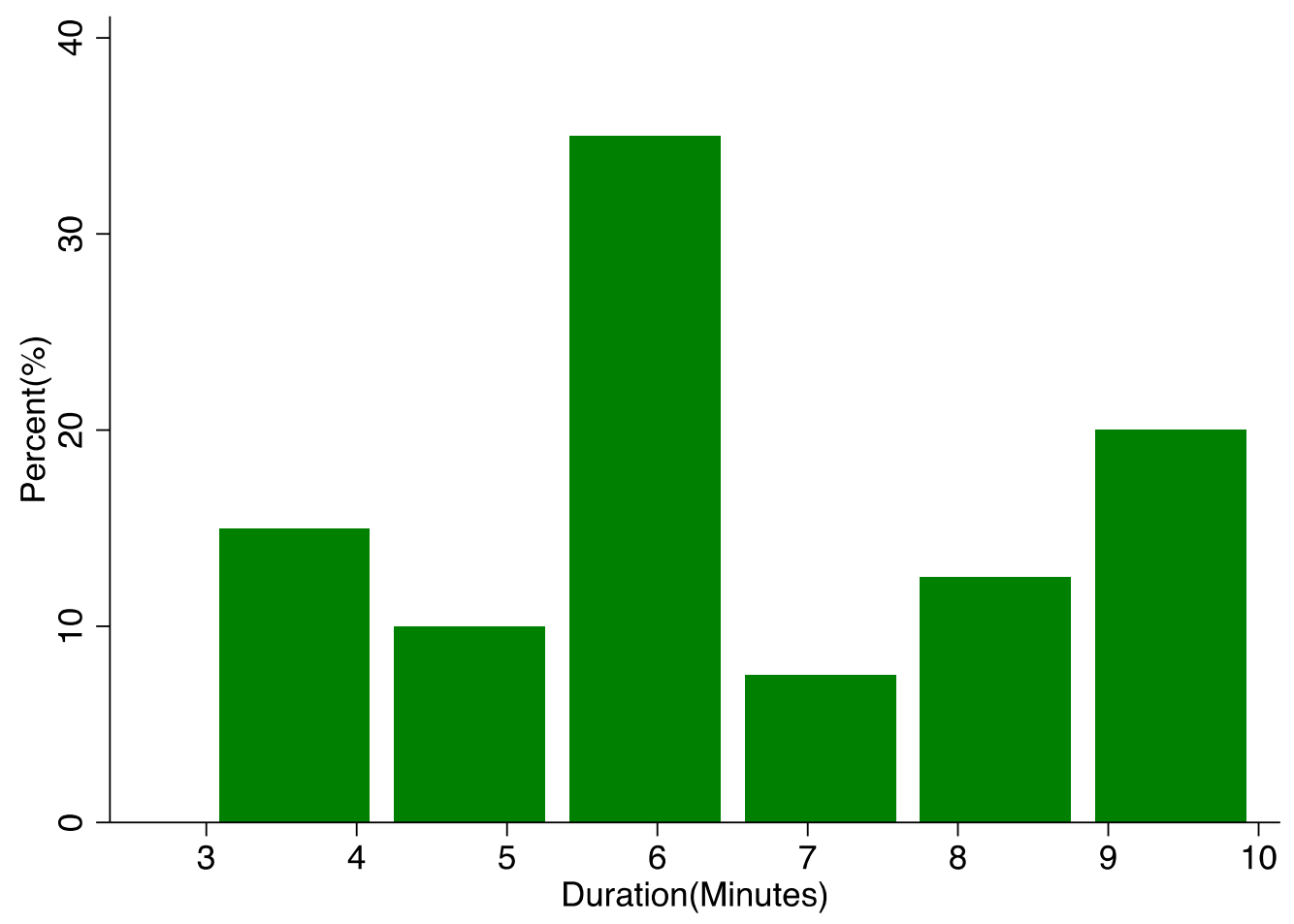

Figure 20. A per cent histogram of taxi durations in 40 records that arrived at Hainan General Hospital, drawn by Stata.

It can be seen that most trips to Hainan General Hospital were shorter than $10 \mathrm{~min}$. Furthermore, several passengers arrived at Hainan General Hospital at midnight. For instance, the earliest passengers (Record ID: 10695) departed from their home at 1:47 AM and arrived at the hospital at 1:55 AM. And the notations for original data are included in the Appendix A (see Table A3 in Appendix A). For passengers who have a health emergency, it is important to arrive at the hospital as quickly as possible, or they might lose their lives. The fare of the trip was 25 units according to the original data, and the value of the passenger for the fare factor is represented by Formula (70). The value of life is infinitely high and is thus much higher than the value of other kinds of businesses. Thus, the value of the passengers for the business factor can be represented by Formula (71). Based on Formula (28), the utility of the passengers can be calculated by Formula (72):

$$
\begin{gathered}
v\left(\operatorname{Pas}_{t_{1} \sim t_{m}, s_{1} \sim s_{p}}(F)\right)=-25 \\
v\left(\operatorname{Pas}_{t_{1} \sim t_{m}, s_{1} \sim s_{p}}(B)\right) \rightarrow+\infty \\
u\left(\operatorname{Pas}_{t_{1} \sim t_{m}, s_{1} \sim s_{p}}(F), \operatorname{Pas}_{t_{1} \sim t_{m}, s_{1} \sim s_{p}}(B)\right) \rightarrow+\infty
\end{gathered}
$$

In this case, the passenger pays great attention to their health, and people with serious illnesses are willing to leave for hospitals to acquire treatment, even at midnight.

In my opinion, the business factor $B$ is easier to ignore than the fare factor $F$. Business factor represents the business that the subject can do at the special spacetime. For instance, suppose that there is a patient who took a taxi to the hospital at midnight. Does the patient who goes to the hospital really want to go to the hospital? Maybe not. Getting treatment is their real business. Their health is much more valuable than the fare they paid to the taxi driver. 
Thus, their transportation utility is closely related to their health, and, in return, their transportation values are also closely related to the values of their health, which is invaluable.

\subsection{Driver Utility Analyses}

The main reason that drivers drive taxis is for money. However, sometimes it is not worth engaging in a trip despite the promise of money from the passenger. For instance, the destination might be so far that the driver is unable to return home on time and eat dinner with his or her family. In this section, the taxi departure positions and arrival positions are compared to analyze driver utility.

There are three parts in this section.

(i) Departure positions. The longitudes of the departure positions were in the range $110.153^{\circ}-110.518^{\circ}$, while the latitudes of the departure positions were in the range of $19.892^{\circ}-20.080^{\circ}$ (see Figure 21). In Figure 21, the red borders represent the area of Hainan Province and Haikou City, while blue triangles represent the departure positions.

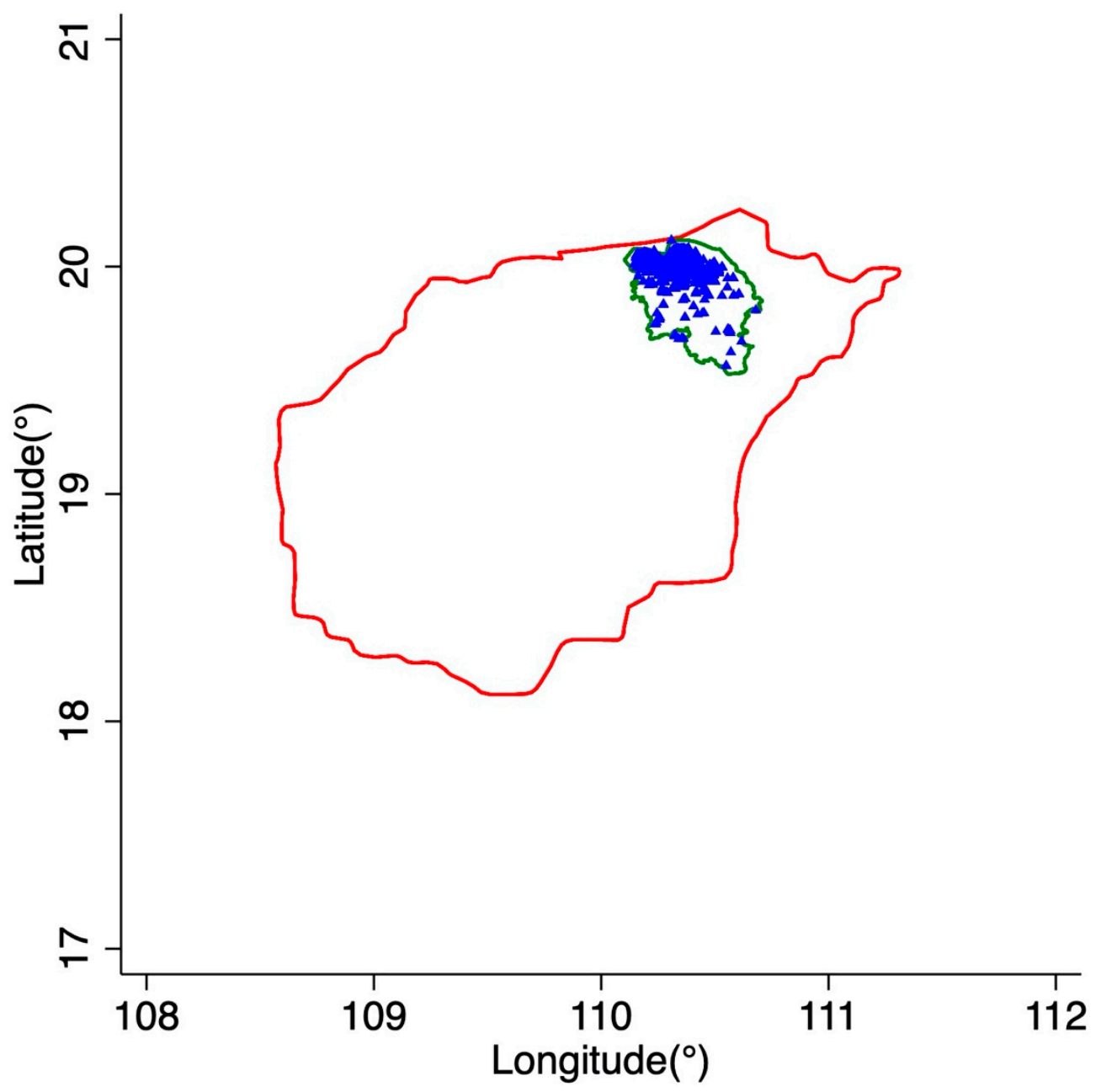

Figure 21. A location map of Hainan Island with 69,174 taxi departure positions inside, drawn by Stata.

(ii) Arrival positions. The longitudes of the departure positions were in the range $110.153^{\circ}-110.583^{\circ}$, while the latitudes of the departure positions were in the range $19.833^{\circ}-20.086^{\circ}$ (see Figure 22 ). In Figure 22, the red borders represent the area of Hainan Province and Haikou City, while the purple triangles represent the arrival positions. 


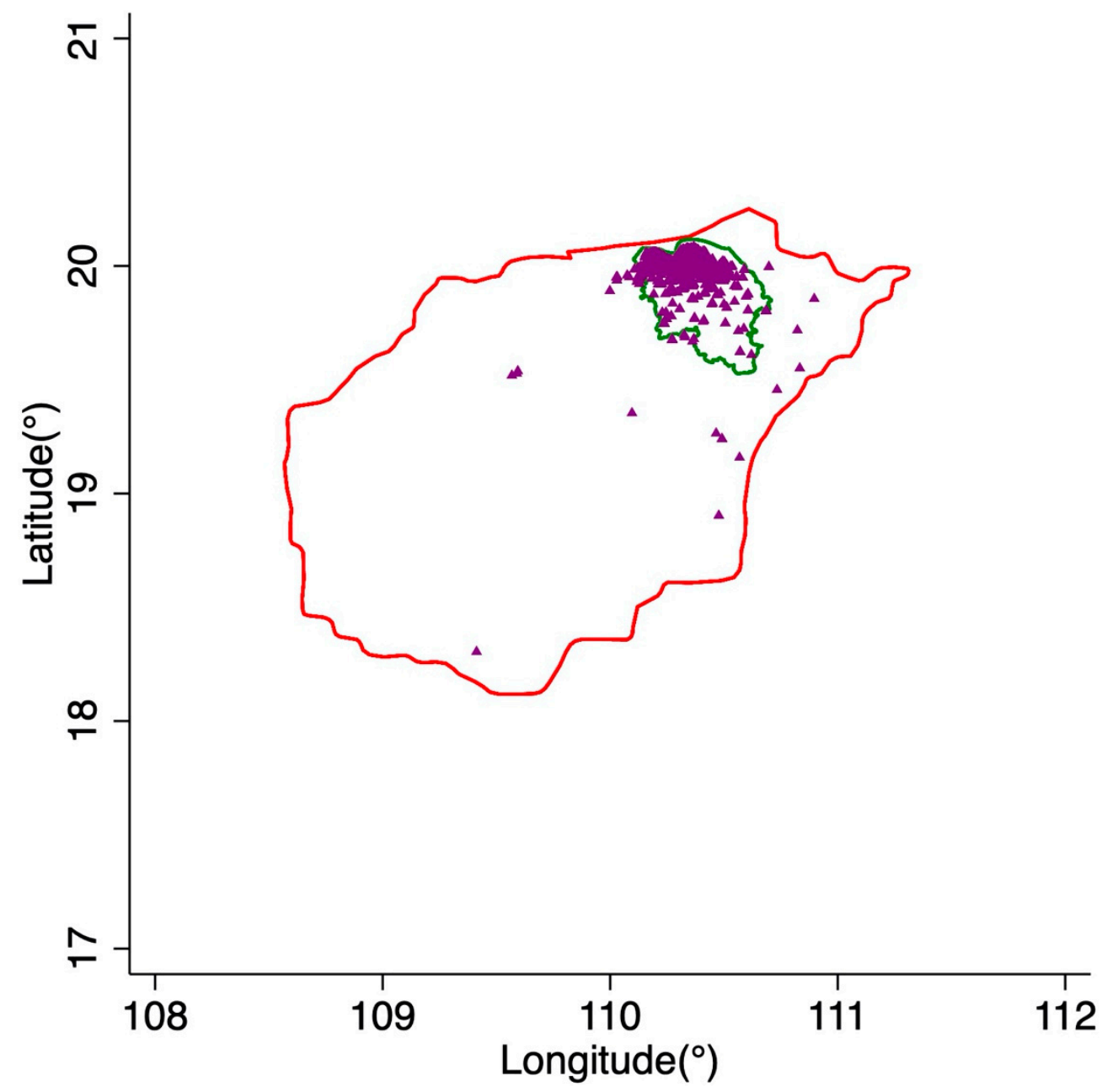

Figure 22. A location map of Hainan Island with 69,174 taxi arrival positions inside, drawn by Stata.

(iii) Distance calculation. The distances of the taxis' movements in the 69,174 records are in the range 0-207 km (see Table 4 and Figure 23), and there are 62,483 records within $10 \mathrm{~km}$ (see Figure 24). In Table 4, the Record ID represents the number of records listed in the original data, and the unit of the distance is in meters. In Figures 23 and 24, the unit of distance is also in meters.

Table 4. Distance calculation of taxi movements in 69,174 records.

\begin{tabular}{cccccccc}
\hline No & $\begin{array}{c}\text { Departure } \\
\text { Longitude }\end{array}$ & $\begin{array}{c}\text { Departure } \\
\text { Latitude }\end{array}$ & $\begin{array}{c}\text { Arrival } \\
\text { Longitude }\end{array}$ & $\begin{array}{c}\text { Arrival } \\
\text { Latitude }\end{array}$ & $\begin{array}{c}\text { Distance } \\
(\boldsymbol{d})\end{array}$ & $\begin{array}{c}\text { Distance } \\
\left(\boldsymbol{d}^{\prime}\right)\end{array}$ & Record ID \\
\hline 1 & 110.3284 & 20.0444 & 110.3284 & 20.0444 & 0 & 0 & 9550 \\
2 & 110.2767 & 19.9789 & 110.2766 & 19.9789 & 11 & 11 & 58725 \\
3 & 110.3353 & 20.0272 & 110.3354 & 20.0272 & 11 & 11 & 33588 \\
4 & 110.4614 & 19.9424 & 110.4613 & 19.9425 & 15 & 15 & 66534 \\
5 & 110.3078 & 20.0299 & 110.3077 & 20.0298 & 15 & 15 & 65645 \\
$\ldots$ & $\ldots$ & $\ldots$ & $\ldots$ & $\ldots$ & $\ldots$ & $\ldots$ & $\ldots$ \\
69170 & 110.4658 & 19.9405 & 109.5941 & 19.5382 & 105,766 & 105,768 & 1014 \\
69171 & 110.4641 & 19.9403 & 109.5898 & 19.5278 & 106,460 & 106,461 & 43015 \\
69172 & 110.4634 & 19.9369 & 109.5681 & 19.519 & 108,828 & 108,830 & 69406 \\
69173 & 110.3579 & 20.05 & 110.4775 & 18.9036 & 120,338 & 120,338 & 32463 \\
69174 & 110.4658 & 19.9405 & 109.4128 & 18.305 & 207,439 & 207,440 & 33969 \\
\hline
\end{tabular}




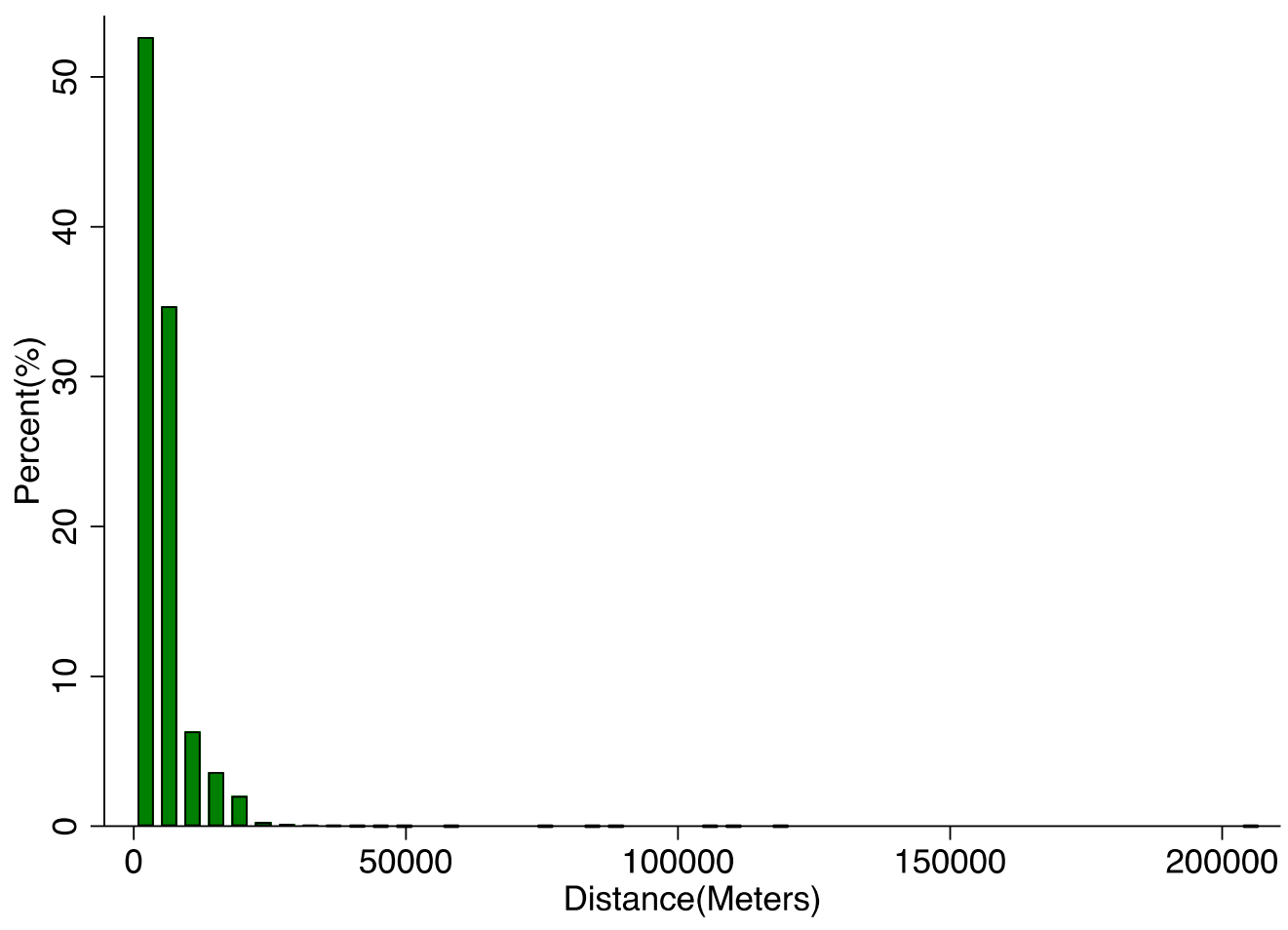

Figure 23. A per cent histogram of taxi movements in 69,174 records, drawn by Stata.

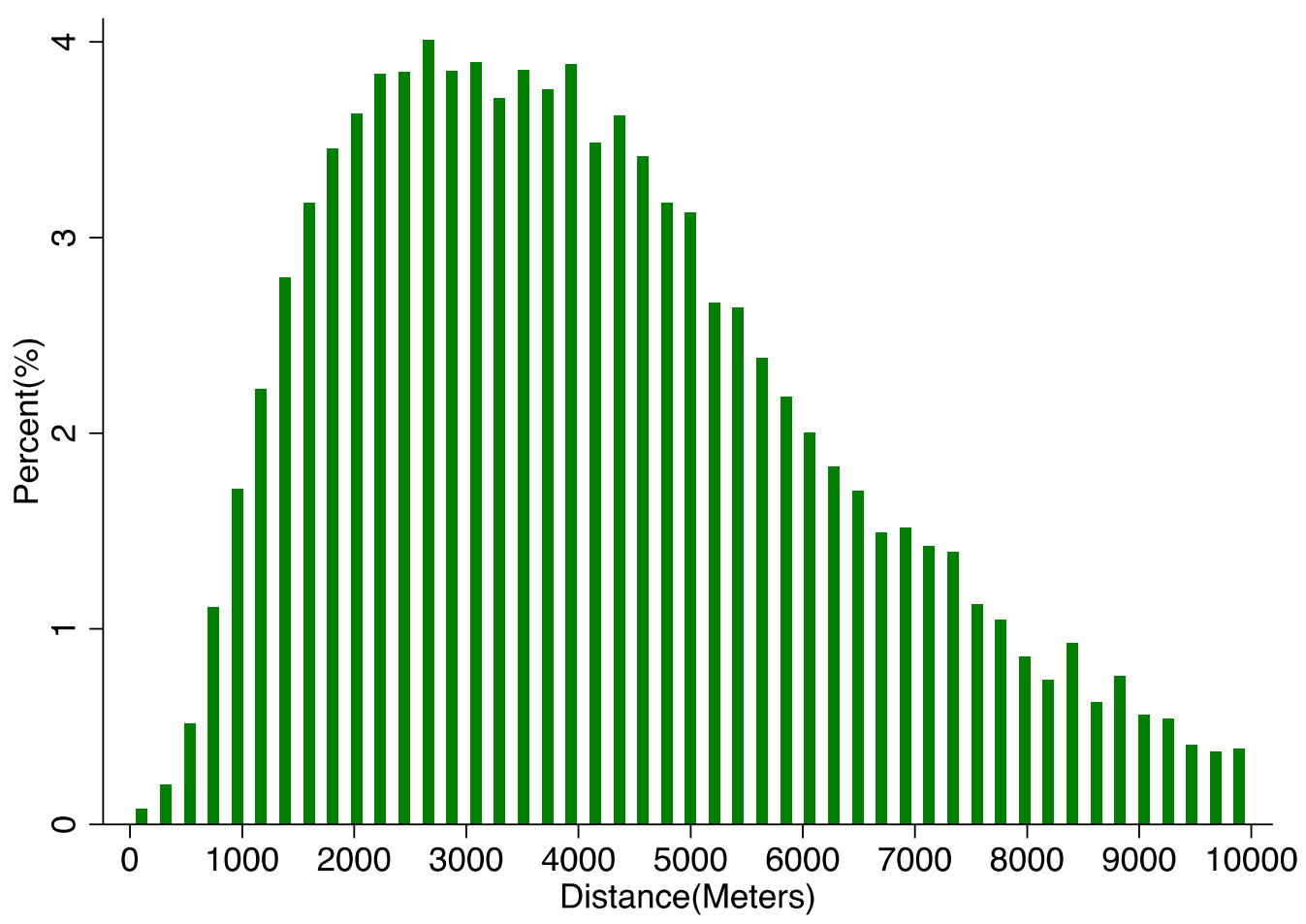

Figure 24. A per cent histogram of taxi movements in 62,483 records, drawn by Stata.

It can be seen that most taxi trips in the 69,174 records were shorter than $10 \mathrm{~km}$. However, several taxis ran very long distances on 1 May 2017. For instance, the longest distance (Record ID: 33969) was greater than $207 \mathrm{~km}$. The taxi departed from Haikou City in the morning and arrived at Sanya City in the evening. Furthermore, several passengers arrived at Hainan General Hospital at midnight.

This indicates that sometimes drivers have to drive their taxis a long distance because of the transportation demands of their passengers. Moreover, the destinations might be not beneficial for 
the drivers. For such taxi drivers, the trips might not be useful, although the drivers would still earn money.

Thus, the transportation utility of drivers is closely related to other aspects et al. money, and, in return, their transportation values are also closely related to aspects other than money.

\subsection{Additional Analyses}

Taxi trips have at least two effects on other objects besides passengers and drivers. One is pedestrians, and the other is the atmosphere in the environment. In this section, taxi speed and taxi pollution are examined to analyze other utility values.

There are two parts in this section.

(i) Pedestrians. Vehicles running at high speeds are dangerous for not only the people inside but also for pedestrians passing by. Thus, speeding taxis have negative effects on pedestrians passing by. For example, it might be unsafe for pedestrians when taxis nearby drive at a high speed. It might also be uncomfortable for pedestrians when taxis nearby make a noise. To analyze the utility to pedestrians, the taxi speeds were calculated via Formula (34). Moreover, flawed data and abnormal data were removed to ensure the integrity of the data. As a result, there were 42,320 records in the range 0-80 km/h and 0-22.2 m/s (see Table 5 and Figure 25). In Table 5, Record ID represents the number of records listed in the original data, and the unit of distance is in meters. In Figure 25, the unit of the average speed is meters per second.

Table 5. Average speed calculation of taxi movements in 42,320 records.

\begin{tabular}{cccccccc}
\hline No & $\begin{array}{c}\text { Departure } \\
\text { Longitude }\end{array}$ & $\begin{array}{c}\text { Departure } \\
\text { Latitude }\end{array}$ & $\begin{array}{c}\text { Arrival } \\
\text { Longitude }\end{array}$ & $\begin{array}{c}\text { Arrival } \\
\text { Latitude }\end{array}$ & $\begin{array}{c}\text { Distance } \\
\left(\boldsymbol{d}^{\prime}\right)\end{array}$ & $\begin{array}{c}\text { Average } \\
\text { Speed }(\bar{v})\end{array}$ & Record ID \\
\hline 1 & 110.2674 & 19.892 & 110.2695 & 19.9010 & 969 & 0.0 & 48815 \\
2 & 110.4614 & 19.9424 & 110.4613 & 19.9425 & 15 & 0.0 & 66534 \\
3 & 110.3433 & 19.9841 & 110.3385 & 20.0055 & 2297 & 0.0 & 63775 \\
4 & 110.3078 & 20.0299 & 110.3077 & 20.0298 & 15 & 0.0 & 65645 \\
5 & 110.3428 & 19.9868 & 110.3443 & 20.0219 & 3667 & 0.0 & 23950 \\
$\ldots$ & $\ldots$ & $\ldots$ & $\ldots$ & $\ldots$ & $\ldots$ & $\ldots$ & $\ldots$ \\
42316 & 110.3677 & 19.9819 & 110.3359 & 20.0201 & 5332 & 22.2 & 16611 \\
42317 & 110.3380 & 20.0256 & 110.3714 & 20.0786 & 6665 & 22.2 & 14629 \\
42318 & 110.3371 & 20.0683 & 110.3449 & 20.0309 & 3999 & 22.2 & 27460 \\
42319 & 110.2848 & 19.9849 & 110.3326 & 19.9882 & 5332 & 22.2 & 58582 \\
42320 & 110.4368 & 19.9673 & 110.4847 & 19.9677 & 5332 & 22.2 & 10414 \\
\hline
\end{tabular}

Due to the lack of original data, we could not determine the instantaneous speeds at every specific moment but only the average speeds. However, it can be seen that some taxis' speeds were sometimes higher than $80 \mathrm{~km} / \mathrm{h}$, which is the speed limit in urban areas. These speeding taxis are dangerous if there are pedestrians passing by.

(ii) Pollution. Taxis have negative effects on the environment because of their pollution. In recent years, the Chinese government has paid much attention to vehicle pollution, with two relevant events. First, the government of Haikou City announced that they accomplished their Taxi Energy Conversion Work on 23 March 2017. According to the report, all the taxis in Haikou must use no more oil but gas instead. Second, the government of Hainan Province published a policy called the Clean Energy Vehicles Campaign on 8 April 2020. According to this policy, all the taxis in Hainan must use clean energy by the end of 2020. The original data of Haikou were collected on 1 May 2017. Thus, all the taxis in this paper used gas. Although gas-based taxis produce less pollution than oil-based taxis, they are both fossil energy-based vehicles and both pollute the environment. Furthermore, clean energy should be hydrogen energy or electrical energy, which is the target of Hainan Province this year. 


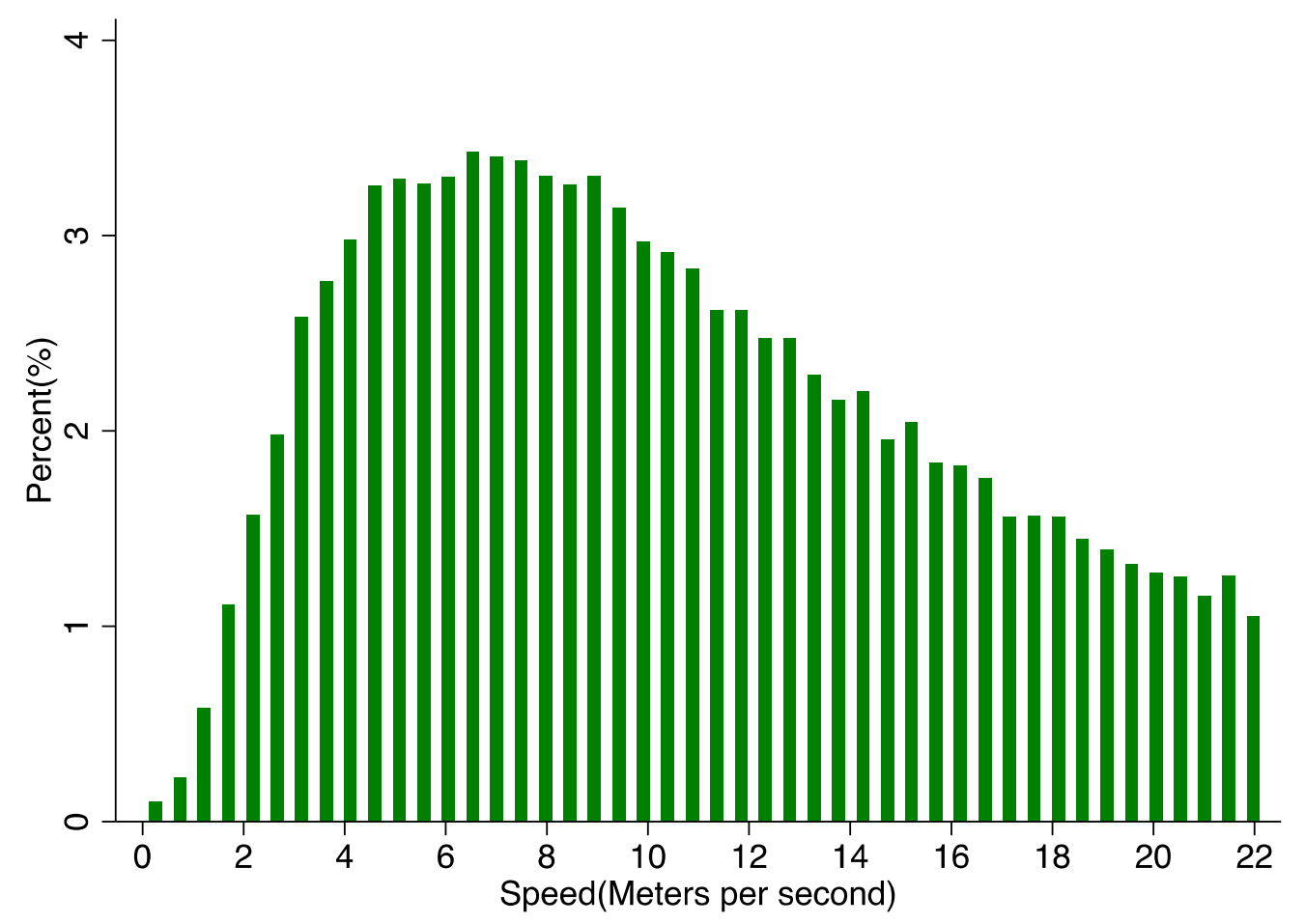

Figure 25. A per cent histogram of taxi average speeds in 42,320 records, drawn by Stata.

Thus, the transportation utility of taxi trips is closely related to aspects other than passengers and drivers. Passengers and drivers might benefit from the trip, while pedestrians passing by and the environment might not.

\section{Discussion}

There are three parts in this section.

(i) Operational Details. Over the course of this research, four operational details had not been contemplated within:

1. During the spatial analysis using ArcGIS Pro (trial version), we found that the function of the spatial analyst tool called Extract Values to Points was unavailable in v2.3.0 but available in v2.4.2. Moreover, some errors in v2.3.0 have been fixed. Moreover, we suggest setting the data type as Double instead of Long when adding the attribute table of border points during the fourth step of border point extraction.

2. In this research, we set $R=6378.1370(\mathrm{~km})$, which represents the radius of the earth (see Section 3.4). However, the radius of the Earth is different in different places. This value is acceptable because the original data were collected in the same place, so the value of the Earth's radius was uniform in the original data.

3. In this paper, the values of the longitudes and latitudes were rounded to four decimal places, and the values of altitudes were rounded to an integer. The distances were rounded to an integer, and the average speeds were rounded to 1 decimal place.

4. In Figure 19, there are two numbers on the bottom. Due to Stata length limits, these two numbers have been automatically rounded to 3 decimal places. The number 110.283 on the left should be 110.2828 in fact, and the number 110.284 on the right should be 110.2844 in fact.

(ii) Limitations. There are at least seven main limitations to this research, which are described as follows.

1. The original data had limitations. First, all the order_id values in the original data were masked as the same number, 17,600,000,000,000 (see Table A3 in Appendix A). Thus, we could not distinguish 
taxis or analyze their specific trajectories. Second, several data in the original data set were empty. For instance, order_make.day $=0$ (Record ID: 70038). Third, several data in the original data set were found to be abnormal when observing them. For instance, departure_time was later than arrive_time (Record ID: 1), and starting_lng $=2.2946$ (Record ID: 28087). Fourth, some data in the original data set were found to be abnormal when performing calculations. For instance, the average speed was $52.97 \mathrm{~m} / \mathrm{s}$ (Record ID: 8334). This is impossible for taxis and indicates that the departure_time or arrive_time of the taxi (Record ID: 8334) might be wrong. We removed these flawed data and obtained 69,174 records from the 70,044 records in the original data set when analyzing the positions and obtained 42,320 records when analyzing the average speeds. This is acceptable, but we would have analyzed more if the original data were better.

2. The original data were not fully applied. A total of 197 taxis arrived at Meilan International Airport and 40 taxis arrived at Hainan General Hospital. These numbers are quite small compared with the total trips in the 70,044 records and 69,174 records after cleaning. This indicates that huge amounts of original data were not applied in the section of the application.

3. The Transportation Utility Method had limitations. First, the values of the four factors in the sample were set to share the same units (see Section 3.1). However, it is difficult to harmonize the units of the values for various factors. For instance, the values of lives are invaluable (see Section 5.2). Thus, it is difficult for us to measure all the values accurately. This is acceptable because we were able to ensure the priority of the values instead. Second, all the taxis that arrived at the area of Hainan General Hospital on 1 May in 2017 were presumed to contain passengers that needed medical treatments. However, it is also possible that the passengers were doctors at Hainan General Hospital who took taxis to work. This is acceptable because we found several passengers who arrived at Hainan General Hospital at midnight (see Section 5.2).

4. The research objects were not comprehensive. In this paper, multiple utility values were extracted from analyses based on GPS-equipped taxi data in Haikou. However, taxis are only one constituent of the urban PT system among others such as buses, trams, subways, public bicycles, etc. Due to the limits of the data source, the perspectives of other modes of public transportation were not mentioned in this paper.

5. The distances calculated by the formulas were not accurate. Due to the limits of the data source, the taxi trajectories were not available. Thus, the actual travel routes of the taxis over the road network could not be calculated. As a result, the distances between the origin and the destination were calculated by formulas and do not indicate the actual travel distance of the vehicle across the road network. Suppose that the actual taxi trajectory is $s_{p} \rightarrow s_{q_{1}} \rightarrow s_{q_{2}} \rightarrow \cdots \rightarrow s_{q_{i}} \rightarrow \cdots \rightarrow s_{q_{n}}$, the actual travel distance of the taxi can be calculated by Formula (73).

$$
d^{\prime}\left(s_{p}, s_{q}\right)=d^{\prime}\left(s_{p}, s_{q_{1}}\right)+\sum_{i=1}^{n-1} d^{\prime}\left(s_{q_{i}}, s_{q_{i+1}}\right)
$$

6. The factors were not comprehensive. Due to the limits of the data source, some factors were not mentioned in this paper. For example, the network infrastructure is one of the important factors in sustainable transport and management. Without a network, it is not possible for passengers and drivers to communicate online with each other. Second, traffic congestion is a common problem in big cities. Utility values are affected by the conditions of traffic congestion to a large extent. For instance, police cars, ambulances, and fire engines may fail in their urgent missions because of traffic congestion. Third, different dates were not considered. The situation of city traffic varies each day. For instance, parks are always more crowded on weekends than on weekdays, and traffic congestion thus more easily occurs in the roads around parks on weekends than on weekdays. Moreover, there are many special dates every year, during which urban transportation peaks may occur. These factors have large influences on planning trips, especially when going to the airport or the hospital. 
7. Urban metrics and urban form were ignored. Due to the limits of the data source, there is no extra data to make comparisons with Haikou City. However, urban metrics and urban form are two important characteristics of cities. Both of them are strongly associated with urban PT systems. For instance, high skyscrapers and narrow streets have negative impacts on the accuracy of GPS in cities, especially in highly concentrated urban areas. Thus, two cities with different urban metrics or urban form have huge differences with each other.

(iii) Application Prospects. The Transportation Utility Method has application prospects in the research field of public transport planning and management. With the rapid progress of advanced technologies, there are increasingly more advanced applications involved in intelligent traffic systems, and it is necessary to consider PT problems from multiple perspectives, including passengers, drivers, economics, and the environment. Over the course of this research, three practical directions emerged, which are described as follows.

1. Improving the utility of passengers. Based on the passenger utility analyses (see Sections 4.2 and 5.2), it can be seen that the transportation utility of passengers is closely related to aspects other than money, such as health. To improve the utility of passengers, we can analyze the trip purposes of passengers by their destinations and analyze their utility based on the Transportation Utility Method. Then we can divide them into various priorities. For instance, we regarded passengers asking to go to the hospital as people with an emergency and gave them the highest priority. Moreover, taxi drivers nearby could help such passengers via online platforms. In this way, taxi demands with high utility are more easily satisfied than taxi demands with low utility. Thus, we can improve the utility of passengers by taxi arrangement based on the Transportation Utility Method.

2. Improving the utility of drivers. Based on the driver utility analyses (see Sections 4.2 and 5.2), it can be seen that the transportation utility of taxi drivers is closely related to aspects other than money, such as destinations. To improve the utility of taxi drivers, we can analyze the willingness of taxi drivers by their real-time locations and the requirements they submit to online platforms and analyze their utility based on the Transportation Utility Method. Then we can send suitable taxi orders to such drivers. For instance, we regarded taxi drivers who accepted fares from Haikou to Sanya in the morning to have a strong willingness for driving back to Haikou in the afternoon. Such drivers have a high priority to accept fares from Sanya to Haikou if there are suitable taxi orders for them. As a result, they can go home on time with money. In this way, we can improve the utility of drivers via taxi management based on the Transportation Utility Method.

3. Improving the environment. Based on additional analyses (see Sections 4.4 and 5.4), it can be seen that the transportation utility of taxi trips is closely related to aspects other than passengers or drivers, such as pedestrians and the environment. To improve the utility of pedestrians, we can analyze the average speeds of drivers using GPS-equipped taxi data and send warnings to taxi drivers who drive at high speeds in urban areas. To improve the utility of the environment, we can ensure that taxis use clean energies instead of fossil energy.

Thus, the Transportation Utility Method has application prospects in the research field of public transport planning and management although there are still some limitations to the model.

\section{Conclusions}

In this study, we proposed the Multiple Utility Method and Transportation Utility Method. We explained the Transportation Utility Method using a sample and developed multiple utility analyses based on the processed data of 69,174 GPS-enabled taxis in Haikou.

There are three parts in this section.

(i) Major findings. The major findings in this article are as follows:

1. Traditional utility methods are not comprehensive. 
2. The transportation utility of passengers is closely related to their businesses, energies.

3. The transportation utility of taxi drivers is closely related to whether their trips are finished, energies, and their businesses.

4. The transportation utility calculated by Transportation Utility Method is more objective and more accurate than by traditional utility methods.

(ii) Contributions. The contributions of this study are as follows:

1. The Multiple Utility Method was built to calculate utility from multiple perspectives. This paper has taken consideration of various factors into the analysis which the traditional method had failed to address. Compared with traditional utility theory, three more variables were adopted to define the subjects and objects involved in the research, as well as their specific factors.

2. The Transportation Utility Method was built based on the Multiple Utility Method to calculate the utility in transportation activities from multiple perspectives. Using the Transportation Utility Method, it is possible to calculate utility for time periods that traditional utility methods cannot solve. Compared with traditional utility theory, five more variables were adopted to define the subjects and objects involved in this research, as well as their specific factors.

3. This study provides a sample for a better description.

4. GPS-equipped taxi data from Haikou were adopted for this research. Based on these data, the Transportation Utility Method was used in practice to calculate utility, including passenger utility analyses, driver utility analyses, and additional analyses.

5. The application prospects and limitations of the Transportation Utility Method were discussed.

(iii) Future directions for this research could focus on four aspects.

1. The methods proposed in this article could be improved by intelligent algorithms.

2. More transportation factors could be taken into consideration to expand the utility analyses.

3. More analyses could be conducted to strengthen the results based on more data, such as time estimations, sensitivity analyses, etc.

4. The methods proposed in this article could be extrapolated to other cities around the world after taking important differences into consideration, including urban metrics, urban form, etc.

Supplementary Materials: The following are available online at http://www.mdpi.com/2071-1050/12/19/8070/s1.

Author Contributions: Conceptualization, J.G.; methodology, J.G.; software, J.G.; validation, J.G.; formal analysis, J.G.; investigation, J.G.; resources, J.G.; data curation, J.G.; writing-original draft preparation, J.G.; writing-review and editing, J.G.; visualization, J.G.; supervision, J.G.; project administration, Q.W.; funding acquisition, J.G. and Q.W. All authors have read and agreed to the published version of the manuscript.

Funding: This research was funded in part by the Strategic Planning Research Project of Ministry of Transport of China, grant number [2018-7-9] and [2018-16-9], in part by the Social Science Major Theory and Reality Research Project of Shanxi Province of China, grant number [2020Z362], in part by the Chang'an University Excellent Doctoral Dissertation Project of Chinese Universities Scientific Fund of China, grant number [300102239718], in part by the Scientific Innovation Practice Project of Postgraduates of Chang'an University, grant number [300103703040].

Acknowledgments: The authors are indebted to Didi Chuxing for providing the original data by GAIA Initiative. The authors are indebted to Vittorio Astarita, Jinjun Tang and anonymous referees for their thoughtful comments that have helped substantially improve this work. The authors are also indebted to Rommel Pagalan, Lienell Chavez, Jeffrey Wang, David Carlton and anonymous editors for providing excellent editing services. Jiawei Gui was rewarded by the National Scholarship of China for doctoral students and appreciated that.

Conflicts of Interest: The authors declare no conflict of interest.

Data Availability: The data collected during the study were provided by Didi Chuxing GAIA Initiative and they were freely available at the website https://gaia.didichuxing.com. In detail, the data of Haikou involved in this paper were freely available at the website https://outreach.didichuxing.com/app-vue/HaiKou?id=999. 


\section{Appendix A}

In Appendix A, 4 notations were presented, including notations for variables (see Table A1), notations for symbols (see Table A2), notations for original data (see Table A3), and notations for legends in the sample (see Figure A1). In detail, the Record ID in notations for original data was 10695.

Table A1. Notations for variables.

\begin{tabular}{|c|c|}
\hline Notation & Explanation \\
\hline$i, j, k, l, m, n, p, q$ & Serial numbers with no meaning \\
\hline$J, K, L$ & The maximum in the series of $j, k, l$ \\
\hline$u$ & The utility \\
\hline$x$ & The consumption of the first commodity in traditional utility theories \\
\hline$y$ & The consumption of the second commodity in traditional utility theories \\
\hline sub & The subject \\
\hline$s u b_{i}$ & The subject whose serial number is $i$ \\
\hline$o b$ & The object \\
\hline$o b_{j}$ & The object whose serial number is $j$ \\
\hline$c$ & The factor \\
\hline$c_{k}, c_{l}$ & The factor whose serial number is $k$ or $l$ \\
\hline$z$ & One of participants and derivatives \\
\hline$v$ & The value \\
\hline$t$ & The time \\
\hline$s$ & The space \\
\hline$V$ & The total value \\
\hline $\mathrm{O}$ & The center of the rectangular coordinate system/The center of the earth \\
\hline$P$ & The location \\
\hline$P_{i}$ & The location of taxis \\
\hline$\rho$ & The radial distance \\
\hline$R$ & The radius of the earth \\
\hline$h_{i}$ & The altitude of the location of taxis \\
\hline$\theta$ & The polar angle \\
\hline$\theta_{i}$ & The longitude of the location of taxis \\
\hline$\varphi$ & The azimuthal angle \\
\hline$\varphi_{i}$ & The latitude of the location of taxis \\
\hline$d$ & The distance between two locations of taxis \\
\hline$d^{\prime}$ & The distance between two locations of taxis considering altitude \\
\hline $\bar{v}$ & The average speed of taxis \\
\hline$v^{\prime}$ & The value under a new situation \\
\hline
\end{tabular}

Table A2. Notations for symbols.

\begin{tabular}{cc}
\hline Notation & Explanation \\
\hline Pas & The passenger \\
Dri & The taxi driver \\
Taxi & The taxi \\
Tree & The trees in the environment \\
$F$ & The fare factor \\
$B$ & The business factor \\
$E$ & The energy factor \\
$P$ & The pollution factor \\
\hline
\end{tabular}


Table A3. Notations for original data.

\begin{tabular}{ccc}
\hline ID & Explanation & Example \\
\hline $\begin{array}{c}\text { order_id } \\
\text { city_id } \\
\text { district }\end{array}$ & Masking order ID & 17600000000000 \\
county & City ID & 83 \\
order_make.year & District ID & 898 \\
order_make.month & County ID & 460106 \\
order_make.day & The year of the order & 2017 \\
departure_time & The month of the order & 5 \\
starting_lng & The day of the order & 1 \\
starting_lat & The time of the departure & $01: 47: 00$ \\
arrive_time & The longitude of the departure & 110.3359 \\
dest_lng & The latitude of the departure & 20.0358 \\
dest_lat & The time of the arrive & $01: 55: 00$ \\
pre_total_fee & The longitude of the arrive & 110.2842 \\
\hline
\end{tabular}

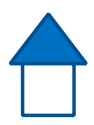

P p
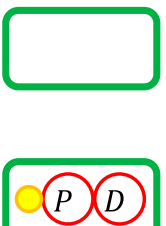

Departure Position (Blue)

Passenger (P)

Tree

Taxi

Taxi with Driver and Passenger

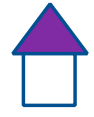

(D)

Money Paid for the Trip

Taxi with Driver (Before Trip)

Taxi with Driver (After Trip)

Figure A1. Notations for legends in the sample.

\section{References}

1. Eboli, L.; Mazzulla, G. Relationships between rail passengers' satisfaction and service quality: A framework for identifying key service factors. Public Transp. 2015, 7, 185-201. [CrossRef]

2. Kim, C.; Goh, S.; Choi, M.S.; Lee, K.; Choi, M.Y. Hub-Periphery Hierarchy in Bus Transportation Networks: Gini Coefficients and the Seoul Bus System. Sustainability 2020, 12, 7297. [CrossRef]

3. Ko, Y.D.; Oh, Y. Efficient Deployment Design of Wireless Charging Electric Tram System with Battery Management Policy. Sustainability 2020, 12, 2920. [CrossRef]

4. Wang, Z.R.; Ma, W.B.; Chan, A. Exploring the Relationships between the Topological Characteristics of Subway Networks and Service Disruption Impact. Sustainability 2020, 12, 3960. [CrossRef]

5. Macioszek, E.; Swierk, P.; Kurek, A. The Bike-Sharing System as an Element of Enhancing Sustainable Mobility-A Case Study based on a City in Poland. Sustainability 2020, 12, 3285. [CrossRef]

6. Lee, H.W.; Kim, K.C.; Lee, J. Review of maglev train technologies. IEEE Trans. Magn. 2006, 42, 1917-1925.

7. Campos, J.; de Rus, G. Some stylized facts about high-speed rail: A review of HSR experiences around the world. Transp. Policy 2009, 16, 19-28. [CrossRef]

8. Lu, L.G.; Han, X.B.; Li, J.Q.; Hua, J.F.; Ouyang, M.G. A review on the key issues for lithium-ion battery management in electric vehicles. J. Power Sources 2013, 226, 272-288. [CrossRef]

9. Sparrow, R.; Howard, M. When human beings are like drunk robots: Driverless vehicles, ethics, and the future of transport. Transp. Res. Part C Emerg. Technol. 2017, 80, 206-215. [CrossRef] 
10. Tong, L.; Zhou, L.S.; Liu, J.T.; Zhou, X.S. Customized bus service design for jointly optimizing passenger-to-vehicle assignment and vehicle routing. Transp. Res. Part C Emerg. Technol. 2017, 85, 451-475. [CrossRef]

11. Zeng, Y.; Zhang, R.; Lim, T.J. Wireless Communications with Unmanned Aerial Vehicles: Opportunities and Challenges. IEEE Commun. Mag. 2016, 54, 36-42. [CrossRef]

12. Campos-Sanchez, F.S.; Chillon, P. Spatial patterns of tourist accommodation location through complementary and integrated analyses: GIS, space syntax and web-scraping. Bol. Asoc. Geogr. Esp. 2020, 84, 2807. [CrossRef]

13. Choi, S.; Choo, S.; Kim, S. Is the Relationship between Transportation and Communications Industries Complementary or Substitutional? An Asian Countries-Based Empirical Analysis Using Input-Output Accounts. Sustainability 2020, 12, 3085. [CrossRef]

14. Campos-Sanchez, F.S.; Reinoso-Bellido, R.; Abarca-Alvarez, F.J. Sustainable Environmental Strategies for Shrinking Cities Based on Processing Successful Case Studies Facing Decline Using a Decision-Support System. Int. J. Environ. Res. Public Health 2019, 16, 3727. [CrossRef]

15. Balsa-Barreiro, J.; Ambuuhl, L.; Menendez, M.; Pentland, A. Mapping Time-Varying Accessibility and Territorial Cohesion With Time-Distorted Maps. IEEE Access 2019, 7, 41702-41714. [CrossRef]

16. Pinna, F.; Masala, F.; Garau, C. Urban Policies and Mobility Trends in Italian Smart Cities. Sustainability 2017, 9, 494. [CrossRef]

17. Frick, S.A.; Rodriguez-Pose, A. Change in urban concentration and economic growth. World Dev. 2018, 105, 156-170. [CrossRef]

18. Frick, S.A.; Rodriguez-Pose, A. Big or Small Cities? On city size and economic growth. Growth Chang. 2018, 49, 4-32. [CrossRef]

19. Li, T.; Rong, L.L.; Yan, K.S. Vulnerability analysis and critical area identification of public transport system: A case of high-speed rail and air transport coupling system in China. Transp. Res. Part A Policy Pract. 2019, 127, 55-70. [CrossRef]

20. Saez, Y.; Munoz, J.; Canto, F.; Garcia, A.; Montes, H. Assisting Visually Impaired People in the Public Transport System through RF-Communication and Embedded Systems. Sensors 2019, 19, 1282. [CrossRef]

21. Perera, P.; Hewage, K.; Sadiq, R. Electric vehicle recharging infrastructure planning and management in urban communities. J. Clean Prod. 2020, 250, 1-18. [CrossRef]

22. Erdogan, M.; Kaya, I. A systematic approach to evaluate risks and failures of public transport systems with a real case study for bus rapid system in Istanbul. Sust. Cities Soc. 2020, 53, 16. [CrossRef]

23. Macioszek, E.; Kurek, A. The Use of a Park and Ride System-A Case Study Based on the City of Cracow (Poland). Energies 2020, 13, 3473. [CrossRef]

24. Bartlomiejczyk, M. Smart Grid Technologies in Electric Power Supply Systems of Public Transport. Transport 2018, 33, 1144-1154. [CrossRef]

25. Thoma, R.S.; Andrich, C.; Del Galdo, G.; Dobereiner, M.; Hein, M.A.; Kaske, M.; Schafer, G.; Schieler, S.; Schneider, C.; Schwind, A.; et al. Cooperative Passive Coherent Location: A Promising 5G Service to Support Road Safety. IEEE Commun. Mag. 2019, 57, 86-92. [CrossRef]

26. Xylia, M.; Silveira, S. The role of charging technologies in upscaling the use of electric buses in public transport: Experiences from demonstration projects. Transp. Res. Part A Policy Pract. 2018, 118, 399-415. [CrossRef]

27. Li, T.L.; Hui, F.; Liu, C.; Zhao, X.M.; Khattak, A.J. Analysis of V2V Messages for Car-Following Behavior with the Traffic Jerk Effect. J. Adv. Transp. 2020, 9181836, 1-11. [CrossRef]

28. Sheikh, M.S.; Liang, J.; Wang, W.S. An Improved Automatic Traffic Incident Detection Technique Using a Vehicle to Infrastructure Communication. J. Adv. Transp. 2020, 9139074, 1-14. [CrossRef]

29. Sun, L.J.; Axhausen, K.W. Understanding urban mobility patterns with a probabilistic tensor factorization framework. Transp. Res. Part B Methodol. 2016, 91, 511-524. [CrossRef]

30. Xu, W.C.; Zhou, H.B.; Cheng, N.; Lyu, F.; Shi, W.S.; Chen, J.Y.; Shen, X.M. Internet of Vehicles in Big Data Era. IEEE-CAA J. Autom. Sin. 2018, 5, 19-35. [CrossRef]

31. Liu, T.; Ceder, A. Integrated public transport timetable synchronization and vehicle scheduling with demand assignment: A bi-objective bi-level model using deficit function approach. Transp. Res. Part B Methodol. 2018, 117, 935-955. [CrossRef] 
32. Antwi, T.; Quaye-Ballard, J.A.; Arko-Adjei, A.; Osei-wusu, W.; Quaye-Ballard, N.L. Comparing Spatial Accessibility and Travel Time Prediction to Commercial Centres by Private and Public Transport: A Case Study of Oforikrom District. J. Adv. Transp. 2020, 8319089, 1-8. [CrossRef]

33. He, L.; Agard, B.; Trepanier, M. A classification of public transit users with smart card data based on time series distance metrics and a hierarchical clustering method. Transp. A Transp. Sci. 2020, 16, 56-75. [CrossRef]

34. Tang, J.J.; Zhang, X.S.; Yin, W.Q.; Zou, Y.J.; Wang, Y.H. Missing data imputation for traffic flow based on combination of fuzzy neural network and rough set theory. J. Intell. Transp. Syst. 2020, 24, 1-16. [CrossRef]

35. Ghahramani, M.; Zhou, M.C.; Wang, G. Urban sensing based on mobile phone data: Approaches, applications, and challenges. IEEE-CAA J. Autom. Sin. 2020, 7, 627-637. [CrossRef]

36. Liu, T.; Ceder, A. Deficit function related to public transport: 50 year retrospective, new developments, and prospects. Transp. Res. Part B Methodol. 2017, 100, 1-19. [CrossRef]

37. Soest, D.V.; Tight, M.R.; Rogers, C.D.F. Exploring the distances people walk to access public transport. Transp. Rev. 2020, 40, 160-182. [CrossRef]

38. Yang, L.; van Dam, K.H.; Majumdar, A.; Anvari, B.; Ochieng, W.Y.; Zhang, L.F. Integrated design of transport infrastructure and public spaces considering human behavior: A review of state-of-the-art methods and tools. Front. Arch. Res. 2019, 8, 429-453. [CrossRef]

39. Shang, H.Y.; Liu, Y.P.; Huang, H.J.; Guo, R.Y. Vehicle Scheduling Optimization considering the Passenger Waiting Cost. J. Adv. Transp. 2019, 2019, 1-13. [CrossRef]

40. Jiang, F.Z.; Thilakarathna, K.; Mrabet, I.; Kaafar, M.A.; Seneviratne, A. uStash: A Novel Mobile Content Delivery System for Improving User QoE in Public Transport. IEEE Trans. Mob. Comput. 2019, 18, 1447-1460. [CrossRef]

41. Salonen, A.O.; Haavisto, N. Towards Autonomous Transportation. Passengers' Experiences, Perceptions and Feelings in a Driverless Shuttle Bus in Finland. Sustainability 2019, 11, 588. [CrossRef]

42. Bosehans, G.; Walker, I. Do supra-modal traveller types exist? A travel behaviour market segmentation using Goal framing theory. Transportation 2020, 47, 243-273. [CrossRef]

43. Yap, M.; Cats, O.; van Arem, B. Crowding valuation in urban tram and bus transportation based on smart card data. Transp. A Transp. Sci. 2020, 16, 23-42. [CrossRef]

44. Virojboonkiate, N.; Chanakitkarnchok, A.; Vateekul, P.; Rojviboonchai, K. Public Transport Driver Identification System Using Histogram of Acceleration Data. J. Adv. Transp. 2019, 6372597, 1-15. [CrossRef]

45. Mokarami, H.; Alizadeh, S.S.; Pordanjani, T.R.; Varmazyar, S. The relationship between organizational safety culture and unsafe behaviors, and accidents among public transport bus drivers using structural equation modeling. Transp. Res. Part F Traffic Psychol. Behav. 2019, 65, 46-55. [CrossRef]

46. Kang, A.S.; Jayaraman, K.; Soh, K.L.; Wong, W.P. Convenience, flexible service, and commute impedance as the predictors of drivers' intention to switch and behavioral readiness to use public transport. Transp. Res. Part F Traffic Psychol. Behav. 2019, 62, 505-519. [CrossRef]

47. Plano, C.; Behrens, R.; Zuidgeest, M. Towards evening paratransit services to complement scheduled public transport in Cape Town: A driver attitudinal survey of alternative policy interventions. Transp. Res. Part A Policy Pract. 2020, 132, 273-289. [CrossRef]

48. Algaba, E.; Fragnelli, V.; Llorca, N.; Sanchez-Soriano, J. Horizontal cooperation in a multimodal public transport system: The profit allocation problem. Eur. J. Oper. Res. 2019, 275, 659-665. [CrossRef]

49. Cigu, E.; Agheorghiesei, D.T.; Gavriluta, A.F.; Toader, E. Transport Infrastructure Development, Public Performance and Long-Run Economic Growth: A Case Study for the Eu-28 Countries. Sustainability 2019, 11, 67. [CrossRef]

50. Pavon, N.; Rizzi, L.I. Road infrastructure and public bus transport service provision under different funding schemes: A simulation analysis. Transp. Res. Part A Policy Pract. 2019, 125, 89-105. [CrossRef]

51. Wang, J.W.; Sun, L.J. Dynamic holding control to avoid bus bunching: A multi-agent deep reinforcement learning framework. Transp. Res. Part C Emerg. Technol. 2020, 116, 12. [CrossRef]

52. Wołek, M.; Wolański, M.; Bartłomiejczyk, M.; Wyszomirski, O.; Grzelec, K.; Hebel, K. Ensuring sustainable development of urban public transport: A case study of thetrolleybus system in Gdynia and Sopot (Poland). J. Clean Prod. 2020, 279, 1-14.

53. Guo, Y.Y.; Liu, P.; Liang, Q.Y.; Wang, W. Effects of parallelogram-shaped pavement markings on vehicle speed and safety of pedestrian crosswalks on urban roads in China. Accid. Anal. Prev. 2016, 95, 438-447. [CrossRef] [PubMed] 
54. Pinna, F.; Murrau, R. Age Factor and Pedestrian Speed on Sidewalks. Sustainability 2018, 10, 84. [CrossRef]

55. Guido, G.; Vitale, A.; Astarita, V.; Giofré, V. Comparison Analysis between Real Accident Locations and Simulated Risk Areas in An Urban Road Network. Safety 2019, 5, 60. [CrossRef]

56. Chowdhury, S. Role of Gender in the Ridership of Public Transport Routes Involving Transfers. Transp. Res. Rec. 2019, 2673, 855-863. [CrossRef]

57. Chowdhury, S.; van Wee, B. Examining women's perception of safety during waiting times at public transport terminals. Transp. Policy 2020, 94, 102-108. [CrossRef]

58. Nesheli, M.M.; Ceder, A.; Ghavamirad, F.; Thacker, S. Environmental impacts of public transport systems using real-time control method. Transp. Res. Part D Transp. Environ. 2017, 51, 216-226. [CrossRef]

59. Duran-Micco, J.; Vermeir, E.; Vansteenwegen, P. Considering emissions in the transit network design and frequency setting problem with a heterogeneous fleet. Eur. J. Oper. Res. 2020, 282, 580-592. [CrossRef]

60. Cuthill, N.; Cao, M.Q.; Liu, Y.Q.; Gao, X.; Zhang, Y.R. The Association between Urban Public Transport Infrastructure and Social Equity and Spatial Accessibility within the Urban Environment: An Investigation of Tramlink in London. Sustainability 2019, 11, 1229. [CrossRef]

61. Ko, Y.D.; Song, B.D.; Oh, Y. Mathematical Analysis of Environmental Effects of Forming a Platoon of Smart Vehicles. Sustainability 2019, 11, 571. [CrossRef]

62. Paulley, N.; Balcombe, R.; Mackett, R.; Titheridge, H.; Preston, J.; Wardman, M.; Shires, J.; White, P. The demand for public transport: The effects of fares, quality of service, income and car ownership. Transp. Policy 2006, 13, 295-306. [CrossRef]

63. Tang, J.J.; Liu, F.; Wang, Y.H.; Wang, H. Uncovering urban human mobility from large scale taxi GPS data. Phys. Stat. Mech. Appl. 2015, 438, 140-153. [CrossRef]

64. Zhan, X.Y.; Hasan, S.; Ukkusuri, S.V.; Kamga, C. Urban link travel time estimation using large-scale taxi data with partial information. Transp. Res. Part C Emerg. Technol. 2013, 33, 37-49. [CrossRef]

65. Kan, Z.H.; Tang, L.L.; Kwan, M.P.; Ren, C.; Liu, D.; Li, Q.Q. Traffic congestion analysis at the turn level using Taxis' GPS trajectory data. Comput. Environ. Urban Syst. 2019, 74, 229-243. [CrossRef]

66. Zhang, X.C.; Zhao, Z.X.; Zheng, Y.; Li, J.Y. Prediction of Taxi Destinations Using a Novel Data Embedding Method and Ensemble Learning. IEEE Trans. Intell. Transp. Syst. 2020, 21, 68-78. [CrossRef]

67. Tang, J.J.; Gao, F.; Liu, F.; Zhang, W.H.; Qi, Y. Understanding Spatio-Temporal Characteristics of Urban Travel Demand Based on the Combination of GWR and GLM. Sustainability 2019, 11, 5525. [CrossRef]

68. Sun, J.; Dong, H.; Qin, G.Y.; Tian, Y. Quantifying the Impact of Rainfall on Taxi Hailing and Operation. J. Adv. Transp. 2020, 7081628, 1-14. [CrossRef]

69. Liu, X.M.; Sun, L.; Sun, Q.X.; Gao, G. Spatial Variation of Taxi Demand Using GPS Trajectories and POI Data. J. Adv. Transp. 2020, 7621576, 1-20. [CrossRef]

70. Ma, X.L.; Wang, Y.H. Development of a Data-Driven Platform for Transit Performance Measures Using Smart Card and GPS Data. J. Transp. Eng. 2014, 140, 12. [CrossRef]

71. Wong, R.C.P.; Szeto, W.Y.; Yang, W.H. Customers' selections between premium electric taxis and liquefied petroleum gas taxis. Transp. Res. Part D Transp. Environ. 2020, 78, 1-13. [CrossRef]

72. Tang, J.J.; Wang, Y.W.; Hao, W.; Liu, F.; Huang, H.L.; Wang, Y.H. A Mixed Path Size Logit-Based Taxi Customer-Search Model Considering Spatio-Temporal Factors in Route Choice. IEEE Trans. Intell. Transp. Syst. 2020, 21, 1347-1358. [CrossRef]

73. Askari, S.; Peiravian, F.; Tilahun, N.; Baseri, M.Y. Determinants of users' perceived taxi service quality in the context of a developing country. Transp. Lett. 2020, 12, 1-13. [CrossRef]

74. Ma, X.L.; Tao, Z.M.; Wang, Y.H.; Yu, H.Y.; Wang, Y.P. Long short-term memory neural network for traffic speed prediction using remote microwave sensor data. Transp. Res. Part C Emerg. Technol. 2015, 54, 187-197. [CrossRef]

75. Ghahramani, M.; Zhou, M.C.; Hon, C.T. Mobile Phone Data Analysis: A Spatial Exploration Toward Hotspot Detection. IEEE Trans. Autom. Sci. Eng. 2019, 16, 351-362. [CrossRef]

76. Dai, Z.; Ma, X.L.; Chen, X. Bus travel time modelling using GPS probe and smart card data: A probabilistic approach considering link travel time and station dwell time. J. Intell. Transp. Syst. 2019, 23, 175-190. [CrossRef]

77. Poo, F.M.; Ledesma, R.D.; Lopez, S.S. The taxi industry: Working conditions and health of drivers, aliterature review. Transp. Rev. 2018, 38, 394-411. [CrossRef] 
78. Skok, W.; Baker, S. Evaluating the impact of Uber on London's taxi service: A critical review of the literature. Knowl. Process Manag. 2019, 26, 3-9. [CrossRef]

79. Bentham, J. An Introduction to the Principles of Morals and Legislation; Oxford University Press: Oxford, UK, 1996.

80. Jevons, W.S. The Theory of Political Economy; Kessinger Publishing: Whitefish, MT, USA, 2010.

81. Menger, C. Grundsätze der Volkswirtschaftslehre; Vdm Verlag Dr. Müller: Chisinau, Moldova, 2006; ISBN 9783865505231.

82. Walras, L. Elements of Pure Economics: Or the Theory of Social Wealth; Routledge: London, UK, 2010.

83. Marshall, A. Principles of Economics: Abridged Edition; Cosimo Classics: New York, NY, USA, 2006.

84. Neumann, J.V.; Morgenstern, O. Theory of Games and Economic Behavior; Princeton University Press: Princeton, NJ, USA, 2007.

85. Arrow, K.J.; Debreu, G. Existence of an Equilibrium for a Competitive Economy. Econometrica 1954, 22, 265-290. [CrossRef]

86. Kalan, O.; Kurkcu, A.; Ozbay, K. Is Additive Utility Function Always a Sufficient Method in the Project Prioritization Process? Bridge Management Perspective. Transp. Res. Rec. 2019, 2673, 284-294. [CrossRef]

87. Francis, D.; Tsang, F.; Erhardt, G.D. Estimating the Cost and Utility of Statewide Travel Models using Scenario-Based Interviews. Transp. Res. Rec. 2019, 2673, 143-153. [CrossRef]

88. Cantelmo, G.; Viti, F. Incorporating activity duration and scheduling utility into equilibrium-based Dynamic Traffic Assignment. Transp. Res. Part B Methodol. 2019, 126, 365-390. [CrossRef]

89. Bigazzi, A.; Lindsey, R. A utility-based bicycle speed choice model with time and energy factors. Transportation 2019, 46, 995-1009. [CrossRef]

90. Hasnine, M.S.; Graovac, A.; Camargo, F.; Habib, K.N. A random utility maximization (RUM) based measure of accessibility to transit: Accurate capturing of the first-mile issue in urban transit. J. Transp. Geogr. 2019, 74, 313-320. [CrossRef]

91. Li, X.P.; Medal, H.; Qu, X.B. Connected infrastructure location design under additive service utilities. Transp. Res. Part B Methodol. 2019, 120, 99-124. [CrossRef]

92. Sharma, B.; Hickman, M.; Nassir, N. Park-and-ride lot choice model using random utility maximization and random regret minimization. Transportation 2019, 46, 217-232. [CrossRef]

93. Khan, Z.; Khan, S.M.; Chowdhury, M.; Safro, I.; Ushijima-Mwesigwa, H. Wireless charging utility maximization and intersection control delay minimization framework for electric vehicles. Comput. Aided Civ. Infrastruct. Eng. 2019, 34, 547-568. [CrossRef]

94. Bachmann, C. Calibrating and Applying Random-Utility-Based Multiregional Input-Output Models for Real-World Applications. Netw. Spat. Econ. 2019, 19, 219-242. [CrossRef]

95. Xia, S.; Wang, P.; Kwon, H.M. Utility-Optimal Wireless Routing in the Presence of Heavy Tails. IEEE Trans. Veh. Technol. 2019, 68, 780-796. [CrossRef]

96. Luo, Q.Y.; Li, C.L.; Luan, T.H.; Wen, Y.Y. Optimal Utility of Vehicles in LTE-V Scenario: An Immune Clone-Based Spectrum Allocation Approach. IEEE Trans. Intell. Transp. Syst. 2019, 20, 1942-1953. [CrossRef]

97. Goebel, D.; Plotz, P. Machine learning estimates of plug-in hybrid electric vehicle utility factors. Transp. Res. Part D Transp. Environ. 2019, 72, 36-46. [CrossRef]

98. Singleton, P.A. Discussing the "positive utilities" of autonomous vehicles: Will travellers really use their time productively? Transp. Rev. 2019, 39, 50-65. [CrossRef]

99. Bukhsh, Z.A.; Stipanovic, I.; Doree, A.G. Multi-year maintenance planning framework using multi-attribute utility theory and genetic algorithms. Eur. Transp. Res. Rev. 2020, 12, 1-13.

100. Moran, A.J.; Jones, W.H. Formulation of Marketing Strategy in Urban Public Transport. Transportation 1975, 4, 209-229. [CrossRef] 
101. Gui, J.; Wu, Q. Taxi Efficiency Measurements Based on Motorcade-Sharing Model: Evidence from GPS-Equipped Taxi Data in Sanya. J. Adv. Transp. 2018, 2018, 4360516. [CrossRef]

102. Gui, J.; Wu, Q. Vehicle Movement Analyses Considering Altitude Based on Modified Digital Elevation Model and Spherical Bilinear Interpolation Model: Evidence from GPS-Equipped Taxi Data in Sanya, Zhengzhou, and Liaoyang. J. Adv. Transp. 2020, 2020, 6301703. [CrossRef]

(C) 2020 by the authors. Licensee MDPI, Basel, Switzerland. This article is an open access article distributed under the terms and conditions of the Creative Commons Attribution (CC BY) license (http://creativecommons.org/licenses/by/4.0/). 